\title{
Early pulmonary response is critical for extra-pulmonary carbon nanoparticle mediated effects: comparison of inhalation versus intra-arterial infusion exposures in mice
}

Koustav Ganguly 1,2, Dariusch Ettehadieh ${ }^{3}$, Swapna Upadhyay ${ }^{1}$, Shinji Takenaka ${ }^{3}$, Thure Adler ${ }^{4}$, Erwin Karg ${ }^{3,5}$, Fritz Krombach ${ }^{6}$, Wolfgang G. Kreyling ${ }^{3}$, Holger Schulz ${ }^{7,8}$, Otmar Schmid ${ }^{3}$ and Tobias Stoeger ${ }^{3 *}$ (D)

\begin{abstract}
Background: The death toll associated with inhaled ambient particulate matter (PM) is attributed mainly to cardiovascular rather than pulmonary effects. However, it is unclear whether the key event for cardiovascular impairment is particle translocation from lung to circulation (direct effect) or indirect effects due to pulmonary particle-cell interactions. In this work, we addressed this issue by exposing healthy mice via inhalation and intra-arterial infusion (IAI) to carbon nanoparticles (CNP) as surrogate for soot, a major constituent of (ultrafine) urban PM.

Methods: Equivalent surface area CNP doses in the blood (30 $\mathrm{mm}^{2}$ per animal) were applied by IAI or inhalation (lung-deposited dose 10,000 $\mathrm{mm}^{2}$; accounting for $0.3 \%$ of lung-to-blood CNP translocation). Mice were analyzed for changes in hematology and molecular markers of endothelial/epithelial dysfunction, pro-inflammatory reactions, oxidative stress, and coagulation in lungs and extra-pulmonary organs after CNP inhalation ( $4 \mathrm{~h}$ and $24 \mathrm{~h}$ ) and CNP infusion ( 4 h). For methodological reasons, we used two different CNP types (spark-discharge and Printex90), with very similar physicochemical properties [ $\geq 98$ and $\geq 95 \%$ elemental carbon; 10 and $14 \mathrm{~nm}$ primary particle diameter; and 800 and $300 \mathrm{~m}^{2} / \mathrm{g}$ specific surface area] for inhalation and IAI respectively.

Results: Mild pulmonary inflammatory responses and significant systemic effects were observed following $4 \mathrm{~h}$ and $24 \mathrm{~h}$ CNP inhalation. Increased retention of activated leukocytes, secondary thrombocytosis, and pro-inflammatory responses in secondary organs were detected following $4 \mathrm{~h}$ and $24 \mathrm{~h}$ of CNP inhalation only. Interestingly, among the investigated extra-pulmonary tissues (i.e. aorta, heart, and liver); aorta revealed as the most susceptible extra-pulmonary target following inhalation exposure. Bypassing the lungs by IAI however did not induce any extra-pulmonary effects at $4 \mathrm{~h}$ as compared to inhalation.

(Continued on next page)
\end{abstract}

\footnotetext{
* Correspondence: tobias.stoeger@helmholtz-muenchen.de

${ }^{3}$ Institute of Lung Biology and Disease, Comprehensive Pneumology Center,

Helmholtz Zentrum München, German Research Center for Environmental

Health, D85764 Neuherberg, Germany

Full list of author information is available at the end of the article
} 
(Continued from previous page)

Conclusions: Our findings indicate that extra-pulmonary effects due to CNP inhalation are dominated by indirect effects (particle-cell interactions in the lung) rather than direct effects (translocated CNPs) within the first hours after exposure. Hence, CNP translocation may not be the key event inducing early cardiovascular impairment following air pollution episodes. The considerable response detected in the aorta after CNP inhalation warrants more emphasis on this tissue in future studies.

Keywords: Inhaled soot, Ultrafine particulate matter, Inflammation, Lung, Heart, Aorta, Cardiovascular, Particle translocation

\section{Background}

Epidemiological studies have linked both short-term and long-term particulate matter (PM) exposures to increased morbidity and mortality [1-4]. The World Health Organization (WHO) estimated over 800,000 premature deaths worldwide per year to be attributed to PM air pollution [5]. Cardiovascular impairments have been identified by several epidemiological studies as a major PM associated health risk accounting for more fatalities than pulmonary effects [6-10]. Ultrafine or nano-sized carbon particles (UfCP; diameter less than $100 \mathrm{~nm}$ ) originating from incomplete combustion processes (soot) have been hypothesized as the major PM constituent contributing of cardiovascular effects [11] (mainly because of their: 1) greater pulmonary deposition and retention efficiency in the lung periphery compared to larger sized particles [12, 13]; 2) enhanced oxidant capacity $[14,15]$; 3) higher pulmonary proinflammatory potential [16, 17]; and 4) higher efficiency to penetrate the epithelium to reach interstitial sites or even translocate to the systemic circulation and secondary organs (such as brain, heart, aorta, liver etc.) [18-24].

Exposure to urban UfCPs has increased dramatically over the last decades primarily due to the technological revolution resulting in increased emissions of combustion-derived ultrafine particles (soot) from traffic, industry, and heating activities [17]. Consequently, the major constituent of urban ultrafine particles is soot, i.e. carbonaceous material consisting of an elemental carbon core surrounded by various types of organic carbon and small fractions of metal, sulfate, and nitrate compounds $[25,26]$. Elemental carbon nanoparticles (CNPs; primary particle diameter $\sim 25 \mathrm{~nm}$ ) constitute the core of combustion derived particles [27] and represent a relevant toxicological surrogate for exhaust particles from diesel engines, if particle surface area is used as dose metric [28, 29]. Motorvehicle emissions consist of a complex mixture of particulate, chemical and gaseous pollutants such as fine particulate matter (PM2.5; diameter $<2.5 \mu \mathrm{m}$ ), ultrafine particles (UFPs; diameter $<0.1 \mu \mathrm{m}$ ), metals, volatile organic material, black carbon, ozone etc. [30]. A major component of urban PM air pollution is CNPs. They constitute the core of combustion derived particles [27] and represents relevant surrogates for exhaust particles from modern diesel engines [28, 29]. Increased use of engineered nanoparticles has made CNP as an evolving source of human exposure [17]. However, it is to be considered that engineered CNPs and ambient UfCPs in spite of their similar sizes $(<100 \mathrm{~nm})$ are likely to have different modes of action, but may also share certain common modes of action, particularly those driven by the elemental carbon core.

Plausible mechanisms of UfCP-mediated cardiovascular effects have been addressed in many studies. We have previously shown that exposing young and healthy mice to high number concentrations of CNPs induces local acute inflammatory effects in the lung [31]. Furthermore, we could reproduce the epidemiological findings of PM-related cardiovascular risks in an experimental setting by exposing spontaneously hypertensive rats (SHRs) with ambient dust and CNPs [30, 32, 33]. We detected not only blood pressure changes and heart rate variability, but our findings also indicated promotion of endothelial dysfunction and thrombogenesis as the plausible causes for cardiovascular impairments triggered by pulmonary CNP deposition [34, 35]. Others have shown that CNP inhalation causes acute vascular effects in healthy and asthmatic subjects, indicated by changes in peripheral blood leukocyte distribution and adhesion molecule expression [36, 37].

It is generally assumed that PM exposure elicits lowgrade systemic inflammation and subsequent changes in vascular function, such as increased blood leukocyte and platelet counts, and fibrinogen levels which in turn can result in cardiovascular impairments [38]. Therefore, endothelial dysfunction, inflammation, pro-inflammatory cytokine imbalance, oxidative stress, and dysregulated coagulation pathways may be considered as the triggering events of cardiovascular impairments due to particulate air pollution. Several hypotheses have been put forward to explain the mechanisms through which inhaled particles can interact with the cardiovascular system $[8,39]$. The classical concept is that inhaled particles locally evoke an inflammatory response in the 
lung with subsequent releases of pro-inflammatory and/ or pro-thrombotic mediators into the circulation [11]. In addition to this indirect effect on circulation and extrapulmonary organs, more recent studies suggest that particularly inhaled insoluble nanoparticles (but not micron-sized particles) are capable of rapid translocation into the circulation $[21,40]$ thereby affecting hemostasis and cardiovascular integrity by direct CNP interaction with circulation and extra-pulmonary organs $[41,42]$. In this direct mode of action, the lungs act as an efficient port of entry of the primary toxin (CNPs in this case), while in the indirect mode of action the lungs act as mediator or even amplifier of a local (pulmonary) inflammatory response yielding systemic effects. The direct mode of action is supported by the findings of Nurkiewicz and colleagues [43] who reported systemic microvascular responses in rats following pulmonary exposure to residual oil fly ash and $\mathrm{TiO}_{2}$ independent of the degree of pulmonary inflammation. In another more direct approach, we have shown that a moderate dose of $10^{7}$ intraarterially infused CNPs induced platelet accumulation in the hepatic microvasculature of mice [34]. This was associated with pro-thrombotic changes on the endothelial surface of hepatic microvessels. Similarly, inhalation of CNPs evoked platelet adhesion and fibrinogen deposition in mice at corresponding doses [35]. However, the key question that still remains to be answered; i.e. whether the extra-pulmonary effects following inhalation of insoluble particles result from molecular events initiated in the lungs (indirect mode) or translocation of particles beyond the lungs (direct mode) drives the extra-pulmonary effects, or both.

The overarching aim was to investigate, if extrapulmonary effects of CNP inhalation can be explained by direct interactions of lung-blood translocated particles on extra-pulmonary tissue (i.e. heart, liver, aorta) or if the local particle-lung cell interaction in lung is the key event. To pursue this, we have compared pulmonary and systemic effects for two routes of CNP application at equivalent dose, namely CNP application directly into the blood stream (intra-arterial infusion/IAI) and pulmonary application (inhalation) with likely subsequent translocation of a small CNP fraction into the blood stream. BALB/cJ mice were assessed after $4 \mathrm{~h}$ and $24 \mathrm{~h}$ inhalation exposure, or $4 \mathrm{~h}$ after IAI. Time points were selected based on our previous studies showing that in lungs, CNPs induced a two-phase inflammatory response after 4 or $24 \mathrm{~h}$ inhalation [31], whereas the extrapulmonary pro-coagulatory impact in the hepatic microvasculature was detected as early as $2 \mathrm{~h}$ after CNP IAI application [34, 35]. Therefore, we sought to systematically and independently investigate the two potential modes of action by applying (i) similar CNPs, as used in several of our previous studies [44-48] and (ii) equivalent doses of CNP in mice via inhalation or intra-arterial infusion (IAI) and subsequent comparison of the effects in the lung, blood, and secondary target organs such as heart, aorta, and liver.

\section{Results}

Our analysis strategy involved different body compartments namely, bronchoalveolar space, lung tissue, blood (cells and plasma), heart, liver and aorta thereby providing a comprehensive assessment of each compartment in terms of endothelial/epithelial activation, inflammation, and oxidative stress, on the protein and gene expression level. According to the current understanding and as previously outlined by Kermanizadeh et al. [49], oxidative stress, inflammation, cytotoxicity and dysfunction of cellular/physiological processes present the likely causal mechanism of toxicological effects in secondary organs following inhalation and eventually translocation of nanoparticles. All data discussed here are compared to the corresponding time-matched control and are statistically significant $(p<0.05)$. In case of transcript or protein expression data, which was generated from pooled tissue samples, we have only discussed molecules with $\geq 2$ fold increased or decreased expression levels [Additional file 1: Table S1].

To sum up the events matching to experimental design timings: The pro-inflammatory response was detectable at the protein level already after the first $4 \mathrm{~h}$ of CNP inhalation exposure. It is plausible that the proinflammatory mediators are released from, i) intracellular stores (vesicles) [50]; or ii) extracellular stores (matrix immobilized) [51]. However neutrophil recruitment to the lungs and development of a pro-inflammatory gene expression signature might take longer time. Thus, a moderate but significant pro-inflammatory gene signature is detected after a $24 \mathrm{~h}$ CNP inhalation. Whereas in case of IAI, pro-inflammatory protein and gene signature is completely absent at $4 \mathrm{~h}$ even if the applied IAI dose is equivalent to the calculated translocated amount within $24 \mathrm{~h}$ of inhalation. Therefore, we believe, by avoiding the $24 \mathrm{~h} \mathrm{IAI}$ time point we implemented the reduction of animal use principle of the "3R-tenet" without significantly compromising scientific quality. Our experimental strategy was also based on our previous experience where we observed that in case of IAI the time point of $2 \mathrm{~h}$ was sufficient to develop platelet - endothelial interactions [34]. Hence, we strategized to investigate at $4 \mathrm{~h}$ after IAI of CNP allowing an additional $2 \mathrm{~h}$ for further downstream effects. The $4 \mathrm{~h}$ time point investigated in this study is also based on the fact that platelet - endothelial interactions have also been detected already $2 \mathrm{~h}$ after CNP inhalation and effects did not increase $8 \mathrm{~h}$ thereafter [34]. 


\section{Pulmonary response}

In line with previous results [30], CNP inhalation caused a moderate, acute inflammatory response in the lungs. Accordingly, BAL fluid analysis revealed a mild but significant neutrophilic granulocyte influx resulting in $10.2 \pm 2.5 \times 10^{3}$ neutrophils (versus $2.5 \pm 0.8 \times 10^{3}$ in controls) in the CNP exposed group after $24 \mathrm{~h}$ inhalation [Fig. 1; Additional file 1: Table S2]. BAL protein concentration was increased after $4 \mathrm{~h} \mathrm{CNP}$ inhalation and returned to basal levels after $24 \mathrm{~h}$ inhalation [Additional file 1: Table S3]. The analysis of BAL cytokine levels revealed an initially decreased concentration of CXCL1 (2.6 fold) after $4 \mathrm{~h}$ inhalation, while CXCL1 was increased 4.5 fold over control levels after $24 \mathrm{~h}$ CNP inhalation, which is in agreement with elevated BAL neutrophil numbers. Other more monocyte/macrophage, but not directly to granulocyte recruitment related cytokines such as CCL2, IL1a and IL12p40 showed non-elevated levels in the CNP exposed animals [Additional file 1: Table S3] thereby supporting the mild nature of the inflammation.

Transcript expression analysis of 59 genes representative of endothelial/epithelial dysfunction, pro-inflammatory reactions, oxidative stress, and coagulation in the lung tissue was performed to characterize the response pattern after inhalation or IAI of CNPs [Fig. 2a, Additional file 1: Table S4]. As shown by the BAL data, CNP inhalation caused a pro-inflammatory signature in lung tissue extracts with elevated levels of fibrinogen $(F g a,-b,-g)$ and cytokine (Il10, Cxcl1, -2, -5) transcript expression after $24 \mathrm{~h}$ CNP inhalation as well as high abundance of proteins associated with inflammation and endothelial/epithelial activation after $4 \mathrm{~h}$ and $24 \mathrm{~h}$ CNP inhalation (Fig. 2a, b). In contrast to inhalation, $4 \mathrm{~h}$ after CNP IAI no proinflammatory changes could be detected in the lungs, indicating that this route of exposure effectively bypassed an inflammatory stimulation of the lung tissue within the $4 \mathrm{~h}$ time window of investigation. Hence, we conclude that IAI application of CNPs resulted in direct extrapulmonary effects only, while inhalation of CNPs may have resulted in both direct pulmonary and indirect extrapulmonary effects.

\section{Blood response}

Hematological analysis revealed increased granulocyte (1.6-fold) and monocyte (1.8-fold) counts after $24 \mathrm{~h}$ CNP inhalation exposure indicating a mild inflammatory, systemic reaction (Fig. 3a, b; Table 1; Additional file 1: Table S5). Following IAI of CNP, only a mild increase in lymphocyte counts (1.3-fold) was detected. Total platelet count was slightly increased by 1.5 -fold after $4 \mathrm{~h}$ and 1.3-fold after $24 \mathrm{~h}$ of CNP inhalation (Fig. 3a, Table 1, Additional file 1: Table S5). Interestingly, only post CNP inhalation the quantity of large platelets was strongly affected showing a $>9$-fold (at $4 \mathrm{~h}$ ) and $>2$ -

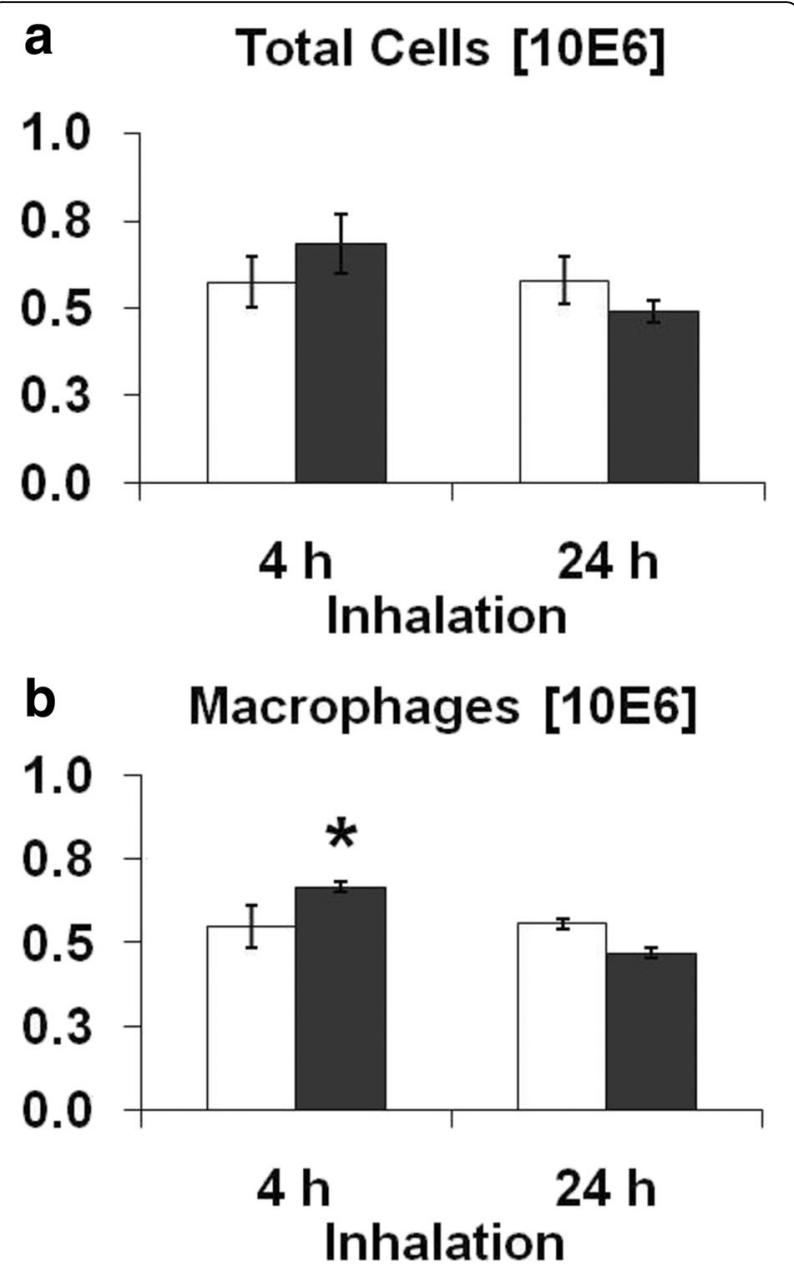

\section{Neutrophil [10E3]}

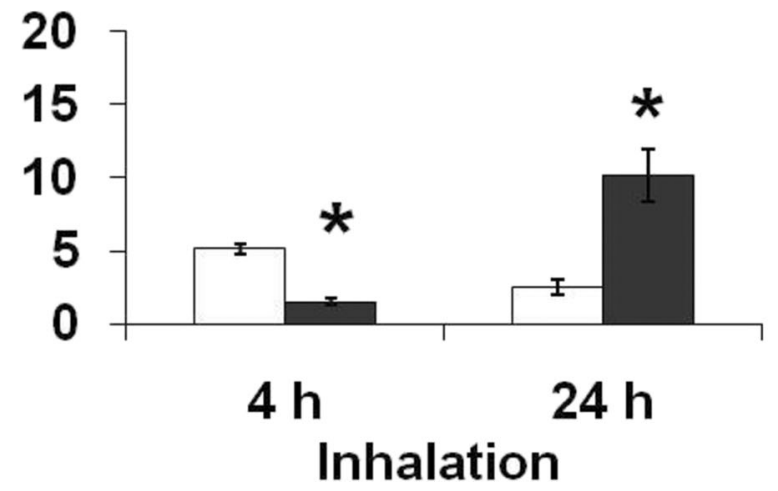

Fig. 1 Analysis of bronchoalveolar lavage (BAL) cell differentials following carbon nanoparticle (CNP) inhalation exposure in BALB/CJ mice compared to control. a. Total BAL cell counts do not exhibit any significant changes. BAL cell analysis following CNP inhalation exposed mice revealed increased macrophages (b) [Control: $5.5 \pm 0.8 \times 10^{5}$ versus $6.7 \pm 0.8 \times 10^{5}$ ] at $4 \mathrm{~h}$ post exposure followed by a strong granulocyte influx (c) [Control: $2.6 \pm 0.8 \times 10^{3}$ versus $10.0 \pm 2.8 \times 10^{3}$ ] at $24 \mathrm{~h}$ post exposure. Data are shown as Mean $\pm \mathrm{SEM} ; n=8$ and asterisks $\left(^{*}\right)$ denote $p<0.05$. White bars: Clean air exposed; Black bars: CNP exposed 
a

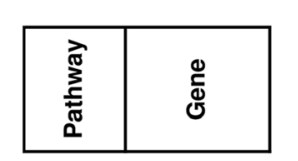

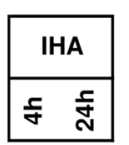

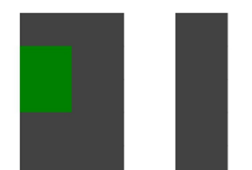

b

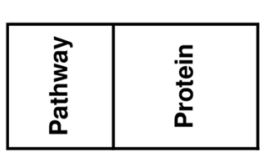

ICAM-1

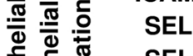

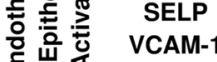
岃这 VCAMF

M MP2

SPP1

SELL TNF-R1

ADIPOQ

CCL2

CCL3

CCL4

CRP

CXCL1

CXCL2

CXCL12

GM-CSF

IFN-g

IL-1b

IL-1a

IL-2

IL-6

IL-12(p40)

IL-13

IL-17

IL-10

IL-1Ra

PDGF-AA

PDGF-BB

RETN

TGF-b1

TNFa
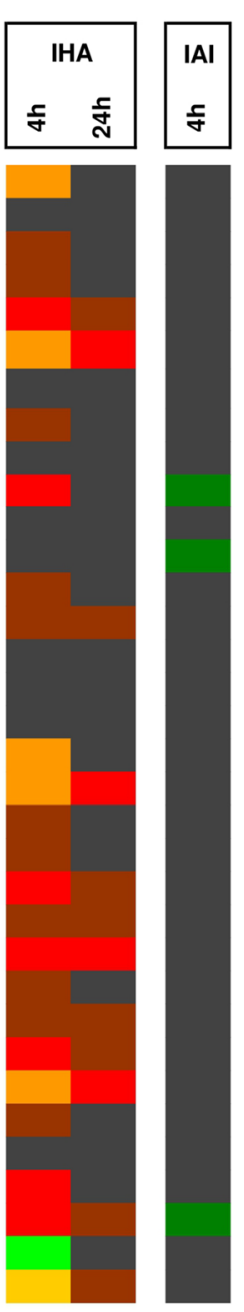

Ptgs 1

Ptgs2

S100a8

Saa3

Spp1

Tnfrsf1a

Csf2

Cxcl1

Cxcl5

IFNg

II10

IIIa

II1b

Tgfb1 Tnf
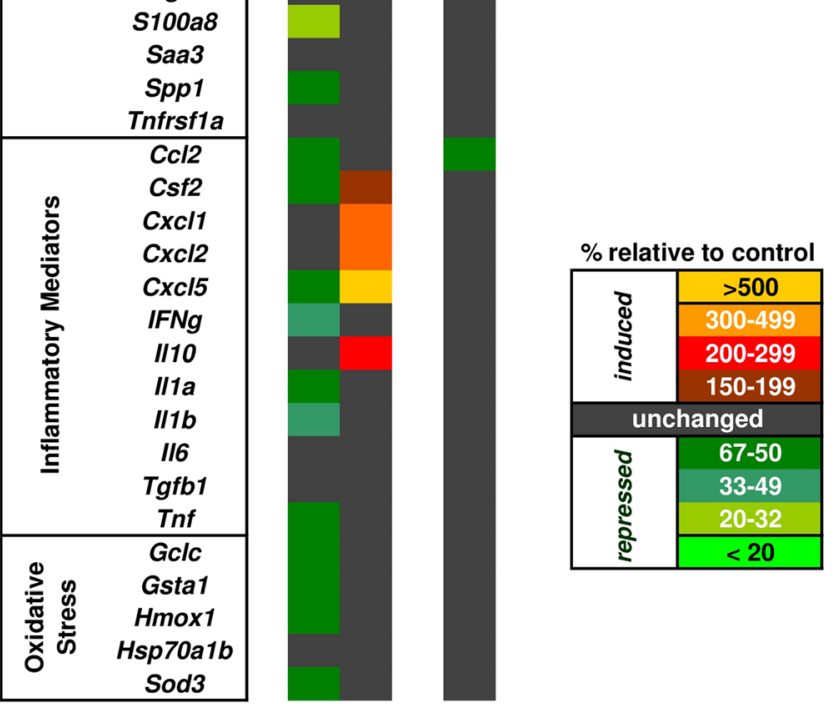

Fig. 2 (See legend on next page.) 
(See figure on previous page.)

Fig. 2 Heatmap representation of lung transcript and protein panel assays following inhalation and intra-arterial infusion exposure of carbon nanoparticles (CNP). a. Transcript expression levels of 59 genes representing epithelial/endothelial activation, inflammatory cell markers, inflammation mediators and oxidative stress are shown. b. Protein expression levels of 34 markers representing epithelial/endothelial activation, inflammatory cell markers, inflammation mediators are shown. Samples were pooled from 4 animals/experimental group for transcript and protein analysis. Expression values are provided as percentage relative to time matched control. Fold changes below 1.5 were considered insignificant and are indicated in black color. IHA: inhalation; IAl: intra-arterial infusion

fold (at $24 \mathrm{~h}$ ) increase. This suggests that $4 \mathrm{~h}$ pulmonary exposure to CNP initiated a reactive thrombocytosis which persisted through $24 \mathrm{~h}$ of CNP inhalation. Thrombocytosis is considered as a predisposing event to atherosclerotic plaque formation. Recently, Tabor et al. [52] reported accelerated arterial thrombus formation in rat models following diesel exhaust particle exposure due to increased platelet activation independent of pulmonary and systemic inflammation or impaired fibrinolytic function. Increase of large platelets indicates the formation of new platelets thereby increasing the total platelet count. Large platelets are also associated with

\section{a \\ Blood cell differentials (inhalation)}

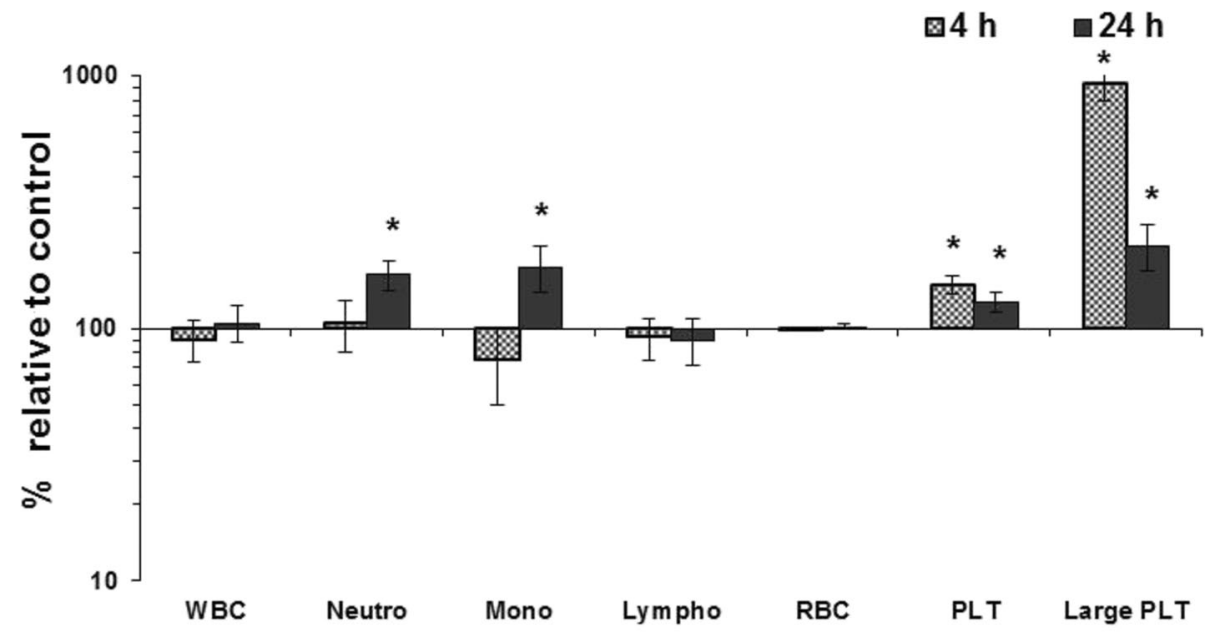

b

Blood cell differentials (infusion)

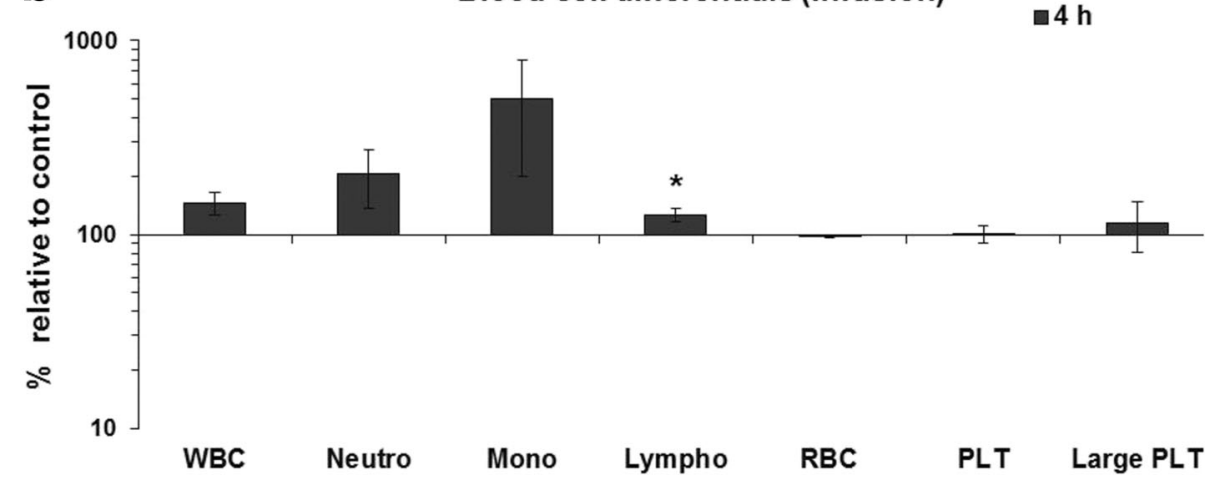

Fig. 3 Hematological analysis of blood samples following inhalation and intra-arterial infusion of carbon nanoparticle (CNP) in mice compared to control. CNP exposure related changes are shown as percentage relative to control. a. Granulocyte and monocyte numbers were increased in the blood following $24 \mathrm{~h}$ CNP inhalation exposure. [Granulocytes: $0.46 \pm 0.09$ versus $0.75 \pm 0.05 \times 10 \mathrm{E} 3$; Monocytes: $0.04 \pm 0.01$ versus $0.07 \pm 0.01 \times 10 \mathrm{E} 3$ cells $/ \mathrm{ml}$ blood]. Platelet counts, particularly that of large platelets, were significantly increased both after $4 \mathrm{~h}$ and $24 \mathrm{~h}$ post exposure periods. [Platelet ( $4 \mathrm{~h}$ post exposure): $810 \pm 87$ versus $1203 \pm 55$; Platelet ( $24 \mathrm{~h}$ post exposure): $869 \pm 97$ versus $1104 \pm 18$ and Large platelet ( $4 \mathrm{~h}$ post exposure): $1.9 \pm 0.4$ versus $17.6 \pm 2.7$; Large platelet ( $24 \mathrm{~h}$ post exposure): $4.3 \pm 1.3$ versus $9.0 \pm 1.3 \times 10 \mathrm{E} 3 \mathrm{cell} / \mathrm{s} / \mathrm{ml}$ blood]. $\mathbf{b}$. Intra-arterial infusion of CNP resulted in increased lymphocyte counts after $4 \mathrm{~h}$ [Lymphocyte: $1.52 \pm 0.07$ versus $1.92 \pm 0.13 \times 10 \mathrm{E} 3 \mathrm{cells} / \mathrm{ml}$ blood] but the platelet count remained unaltered. Data are shown as Mean \pm SEM; inhalation: $n=8$, infusion: $n=6$ and asterisks (*) denote $p<0.05$. WBC: White blood cell; Neutro: neutrophilic granulocytes; Mono: Monocytes; Lympho: Lymphocytes; RBC: Red blood cells; PLT: Platelets; Large PLT: Large platelets 
Table 1 Hematological analysis of blood samples for platelet parameters following inhalation ( $4 \mathrm{~h}$ and $24 \mathrm{~h}$ ) and intra-arterial infusion (4 h) of carbon nanoparticle (CNP) in mice compared to control

\begin{tabular}{|c|c|c|c|c|c|c|c|c|c|}
\hline \multirow[t]{3}{*}{ Platelet Parameters } & \multicolumn{6}{|l|}{ Inhalation } & \multirow{2}{*}{\multicolumn{3}{|c|}{$\frac{\text { Intra-arterial Infusion }}{4 \mathrm{~h}}$}} \\
\hline & \multicolumn{3}{|l|}{$4 \mathrm{~h}$} & \multicolumn{3}{|l|}{$24 \mathrm{~h}$} & & & \\
\hline & Control & CNP & $\mathrm{p}$ & Control & CNP & $\mathrm{p}$ & Control & CNP & $p$ \\
\hline $\mathrm{PLT}(\times 10 \mathrm{E} 3 \mathrm{CELLS} / \mu \mathrm{L})$ & $809.50 \pm 86.95$ & $1203.13 \pm 54.84$ & ${ }^{*} \uparrow$ & $868.50 \pm 96.65$ & $1103.57 \pm 17.77$ & ${ }^{*} \uparrow$ & $902.50 \pm 62.56$ & $909.67 \pm 69.40$ & NS \\
\hline Large PLT (×10E3 CELLS/ $\mu L)$ & $1.88 \pm 0.40$ & $17.63 \pm 2.71$ & $*_{\uparrow} \uparrow$ & $4.25 \pm 1.32$ & $9.00 \pm 1.34$ & ${ }^{*} \uparrow$ & $22.33 \pm 4,72$ & $25.50 \pm 5.60$ & NS \\
\hline MPV (fl) & $5.45 \pm 0.15$ & $7.66 \pm 0.16$ & ${ }^{*} \uparrow$ & $5.99 \pm 0.29$ & $7.04 \pm 0.10$ & ${ }^{*} \uparrow$ & $7.97 \pm 0.30$ & $8.28 \pm 0.58$ & NS \\
\hline РCT (\%) & $0.45 \pm 0.06$ & $0.92 \pm 0.04$ & $*_{\uparrow} \uparrow$ & $0.53 \pm 0.08$ & $0.78 \pm 0.02$ & ${ }^{*} \uparrow$ & $0.73 \pm 0.07$ & $0.74 \pm 0.06$ & NS \\
\hline PDW (\%) & $51.65 \pm 1.15$ & $58.70 \pm 0.79$ & $*^{*} \uparrow$ & $53.63 \pm 2.37$ & $56.99 \pm 1.02$ & NS & $68.83 \pm 2.52$ & $65.25 \pm 1.70$ & NS \\
\hline MPC (g/dl) & $24.93 \pm 0.42$ & $19.86 \pm 0.32$ & ${ }^{*} \downarrow$ & $23.53 \pm 0.72$ & $21.29 \pm 0.21$ & ${ }^{*} \downarrow$ & $19.90 \pm 0.58$ & $19.58 \pm 1.12$ & NS \\
\hline PCDW (g/dl) & $7.41 \pm 0.17$ & $8.10 \pm 0.08$ & ${ }^{*} \uparrow$ & $7.61 \pm 0.24$ & $8.21 \pm 0.06$ & ${ }^{*} \uparrow$ & $7.95 \pm 0.10$ & $7.93 \pm 0.11$ & NS \\
\hline MPM (pg) & $1.23 \pm 0.01$ & $1.26 \pm 0.01$ & ${ }^{*} \uparrow$ & $1.24 \pm 0.01$ & $1.27 \pm 0.01$ & ${ }^{*} \uparrow$ & $1.31 \pm 0.01$ & $1.31 \pm 0.01$ & NS \\
\hline PMDW (pg) & $0.43 \pm 0.01$ & $0.42 \pm 0.01$ & NS & $0.43 \pm 0.01$ & $0.43 \pm 0.01$ & NS & $0.49 \pm 0.01$ & $0.48 \pm 0.01$ & NS \\
\hline
\end{tabular}

PLT platelet, Large PLT large platelet count, MPV mean platelet volume, $P C T$ plateletcrit, $P D W$ platelet distribution width, MPC mean platelet component, $P C D W$ Platelet component distribution width, MPM mean platelet mass, $P M D W$ platelet mass distribution width. Data is shown as Mean \pm SEM; inhalation: $n=8$; infusion: $n=6$; ${ }^{*} p<0.05$; $\uparrow$ : significantly increased; $\downarrow$ : significantly decreased; NS not significant

platelet activation during hemostasis. In accordance, also other platelet indices characterizing platelet volume and granularity (e.g. MPV, PTC, MPC, PCDW and MPM) were altered both after $4 \mathrm{~h}$ and $24 \mathrm{~h}$ CNP inhalation (Table 1). These findings all together support the notion of platelet activation after CNP inhalation. In contrast, platelet count, platelet shape, and platelet activity parameters remained unchanged following IAI (Fig. 3b, Table 1, Additional file 1: Table S5). The recent pioneering work from Lefrançais et al. [53] demonstrated lung as an important site of local platelet biogenesis and a potent reservoir for haematopoietic progenitors. In light of their findings [53], it is plausible that local, pulmonary stress-response to particle inhalation may eventually via local reactive oxygen species (ROS) formation [54] directly lead to rapid increases of blood platelet numbers and thereby increase the risk for cardiac infarction without involving further systemic cytokine elevations and bone marrow activation.

In view of the observed changes in blood neutrophil and monocyte numbers and following the human exposure study from Frampton and colleagues [36], we additionally investigated the surface expression of the adhesion molecules CD11b, CD18 and CD49d to assess the activation status of these circulating leukocytes. Similar to the findings of Framton et al. [36] in human, reduced surface expression of CD49d, CD11b (24 h) and CD18 (4 h) was noted on granulocytes after CNP inhalation $(p<0.05 ; n=8)$. Also for monocytes a reduced CD18 expression was observed after both time points (Fig. 4 a, b). No effect, however, was observed following IAI (Fig. $4 \mathrm{c}, \mathrm{d}$ ). Reduced surface expression of $\beta 1$ and $\beta 2$ integrin leukocyte adhesion molecules CD11b, CD18 and CD49d in peripheral blood monocytes and granulocytes particularly $24 \mathrm{~h}$ post inhalation may indicate an impeding effect on peripheral blood leukocyte distribution, arguing for an increased retention of activated cells in the pulmonary vascular bed due to CNP inhalation. In this context, an inflammatory activation of monocytes and neutrophils in the vascular bed of CNP exposed lungs, with increased expression of CD11b and CD18 integrins, is likely to decrease cell deformability via actin polymerization, again contributing to leukocyte retention and reduced capillary flow [55]. As mentioned before, very similar responses have previously been described in CNP-exposed healthy and asthmatic subjects [36]. In this study also a reduction in pulmonary diffusing capacity for carbon monoxide in CNP exposed individuals was observed, additionally supporting the hypothesis of Frampton and colleagues, of a mismatch in ventilation and pulmonary vascular perfusion and pulmonary capillary flow caused by CNP inhalation.

A panel of 25 protein analytes known to be associated with cardiovascular diseases consisting of acute phase reactants, soluble inflammatory adhesion molecules, inflammation related proteinases, and cytokines were screened in the plasma (Additional file 1: Table S6). Only the plasma levels of the cytokines GM-CSF (2.3 fold) and IL1 $\alpha$ (4.6 fold) were more than 2-fold reduced following CNP inhalation after 4 and $24 \mathrm{~h}$ CNP exposure $(p<0.05 ; n=8$; Fig. $5 a)$. No difference equaling or exceeding a 2 -fold change could be detected following IAI of CNPs (Fig. 5b). Noteworthy, the concentrations of some cytokines and acute phase reactants, i.e. fibrinogen, PAI-1, CXCL1, G-CSF, and IL-6, but also CCL2 and CCL5 were markedly higher in controls of the IAI groups compared to the inhalation scenario, which may indicate an acute phase response caused by the surgical procedure rather than CNP exposure and, thus, may limit the interpretation of these specific endpoints. Yet other cytokines in particular IL-1a and - b, 


\section{a Granulocytes (inhalation)}
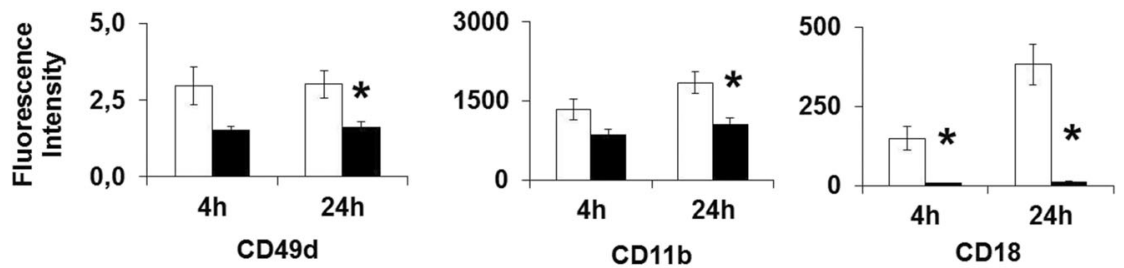

\section{b Monocytes (inhalation)}
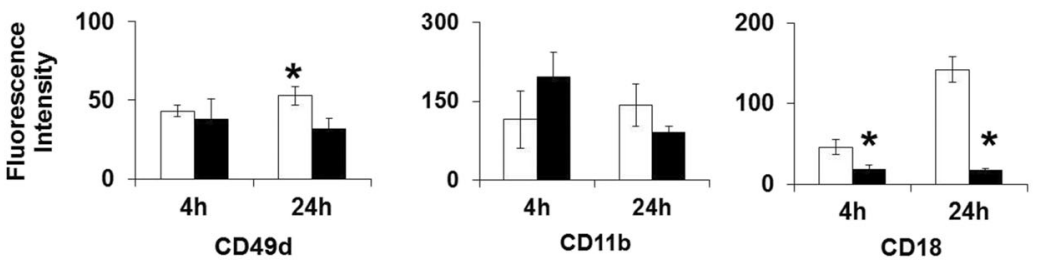

\section{Granulocytes (infusion)}
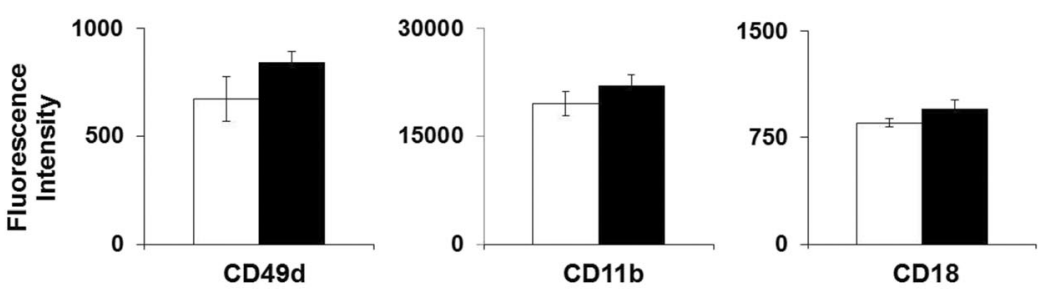

\section{d Monocytes (infusion)}
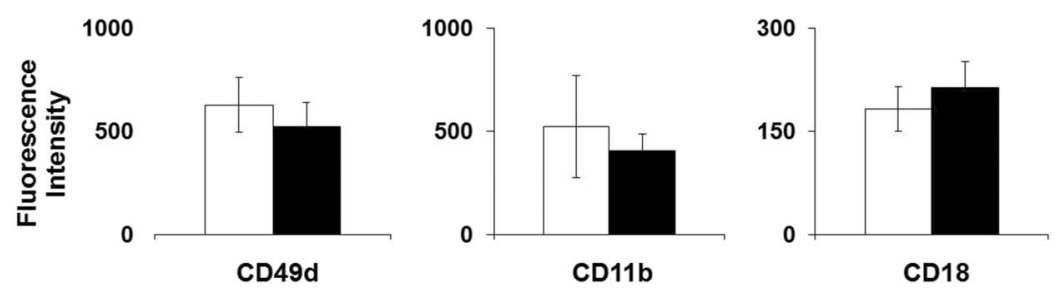

Fig. 4 Characterization of peripheral blood monocytes and leucocytes for surface expression of adhesion molecules following inhalation and intra-arterial infusion of carbon nanoparticle (CNP) in mice compared to control using fluorescent automated cell sorting (FACS). a. Reduced expression of CD49d and CD11b was noted in granulocytes after $24 \mathrm{~h}$ of CNP inhalation exposure whereas CD18 expression was reduced in granulocytes at both $4 \mathrm{~h}$ and $24 \mathrm{~h}$ post inhalation exposure. b. Reduced expression of CD49d in monocytes was observed after $24 \mathrm{~h}$ of CNP inhalation exposure, while reduced CD18 expression in monocytes was noted following both $4 \mathrm{~h}$ and $24 \mathrm{~h}$ post CNP inhalation exposure. $\mathbf{c}$. No altered expression of CD49d, CD11b and CD18 was noted in granulocytes following $4 \mathrm{~h}$ of intra-arterial infusion of CNP. $\mathbf{d}$. No altered expression of CD49d, CD1 1 b and CD18 was noted in monocytes following $4 \mathrm{~h}$ of intra-arterial infusion of CNP. Data are shown as Mean \pm SEM; inhalation: $n=8$, infusion: $n=6$; and asterisks $\left(^{*}\right)$ denote $p<0.05$. White bars: Clean air exposed; Gray bars: CNP exposed

known to show up early during an inflammatory response, remain unchanged between inhalation and IAI controls.

Transcript and protein analysis in extra-pulmonary organs Transcript and protein panel assays were carried out in heart, aorta, and liver tissue (Fig. 6; Additional file 1:
Table S7) to assess and compare the effect of CNP exposure via inhalation and IAI routes. After CNP inhalation transcript analysis of the heart detected several inflammatory cell markers, such as Lcn2, Lgals3, Ly6g, Olr1 and Spp1 as well as the cytokines Cxcl1, Illa and Il6 to be elevated (Fig. 6). In contrast, only the 

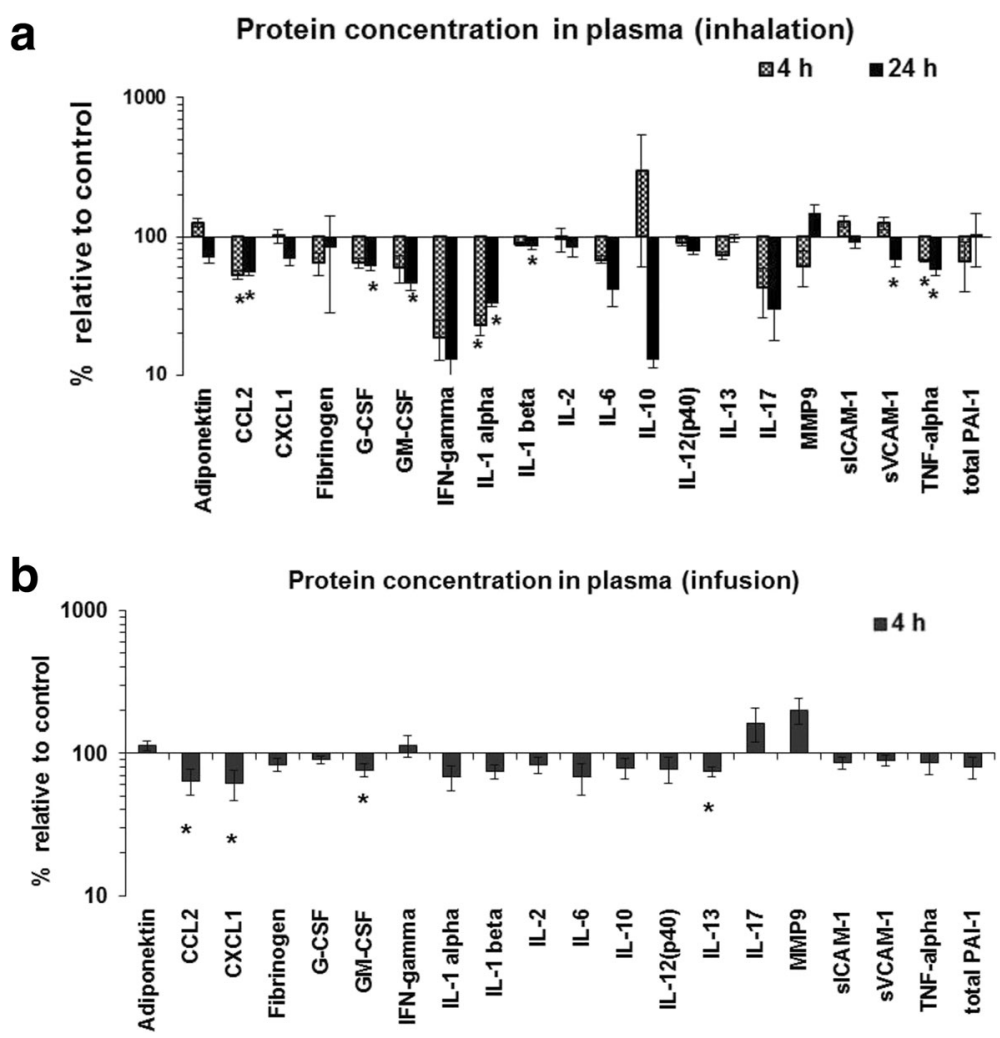

Fig. 5 Expression profiling of acute phase reactants and systemic inflammation markers in the plasma of carbon nanoparticle (CNP) exposed mice compared to control following inhalation and intra-arterial infusion. a. CNP exposure related changes of protein concentrations are shown as percentage relative to control following $4 \mathrm{~h}$ and $24 \mathrm{~h}$ post inhalation is shown. b. CNP exposure related changes of protein concentrations are shown as percentage relative to control following $4 \mathrm{~h}$ post intra-arterial infusion. Data are presented as Mean \pm SEM; inhalation: $n=8$, infusion: $n=6$; and asterisks $\left(^{*}\right)$ denote $p<0.05$

antioxidant response gene Gsta1 was more than 2-fold induced by IAI. Similarly, liver extracts showed increased levels for inflammation-related transcripts Fn1 and Illa after CNP inhalation exposure only. Aorta samples, in fact, revealed the most striking pro-inflammatory RNA signature with 15 markers upregulated after $24 \mathrm{~h}$ of CNP inhalation suggesting endo/epithelial activation and inflammatory leucocyte accumulation. Again, only 3 genes were upregulated after IAI exposure. A similar pattern was observed for the protein profile, with several proinflammatory proteins induced after CNP inhalation in heart $(24 \mathrm{~h})$ and liver $(4 \mathrm{~h})$ samples (SPP1, IL-1b, IL-2, IL13, RETN and TGF-b1), but none after infusion (Fig. 6). Due to limitations in sample weights, aortas were only assessed for mRNA but not protein.

\section{Discussion}

Realizing the broad spectrum of the experiments performed in this work and the corresponding data generated following analysis of pulmonary and extra-pulmonary body compartments, we have explained several aspects of the findings along with the results. Summarizing the events, our findings indicate that equivalent doses of translocated CNP following inhalation - when intraarterially infused - do not cause appreciable extrapulmonary effects. Correspondingly, CNP inhalation induces a very mild inflammatory response in lung tissue with profound systemic effects. Among the studied target organs, the aorta appears to exhibit a high susceptibility to CNP. Increased transcript levels of neutrophil-related chemoattractants ( $\mathrm{Cxcl} 2,-5 ; \mathrm{Lcn} 2)$ and macrophage markers (Ncf1, -2; Saa3, Emr1) indicate plausible accumulation of leukocytes in the aorta. Further, elevated levels of fibrinogens $(F g a,-b,-g)$ suggests triggered homeostatic response and blood leukocyte adhesion. Increased transcript levels of markers associated with atherosclerosis or cardiovascular impairments (Edn1, Selp, Alox5, and Icam1) further indicate plausible detrimental effects of CNP exposure on aortic tissue at $24 \mathrm{~h}$ post inhalation. Increased levels of Alox5, Emr1, Cxcl2, Saa3, Ncf1 and Ncf2 may also suggest inflammatory phagocyte accumulation in the aorta for $24 \mathrm{~h}$ particle inhalation. These findings are supported by the acute protein response in the liver, after $4 \mathrm{~h}$ inhalation and in hematologic parameters, particularly platelet 
a

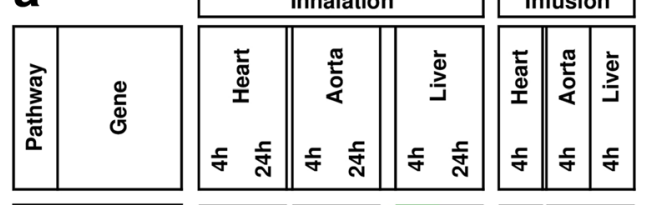
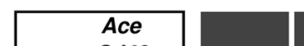

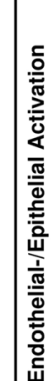

\begin{tabular}{cc} 
든 & Cd40lg \\
Edn1 & F3 \\
$: \frac{1}{0}$ & Fga \\
\hline
\end{tabular}

$\overline{\bar{\sigma}} \quad F g a$

$\begin{array}{cc}\text { Fgg } \\ \text { 竞 } & \text { Fn1 } \\ \text { Icam1 } & \text { Icam }\end{array}$

$\begin{array}{rr}\frac{\omega}{\frac{1}{\omega}} & \text { Icam1 } \\ \frac{\mathrm{O}}{\mathrm{a}} & \text { Nos3 }\end{array}$

ㅎํㅇ Selp

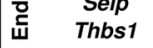

Vcam1

Vwf

Cd68

Emr1

Itgam

Lcn2

LdIr

Lgals3

Lta4h

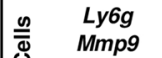

บ $\quad$ Ncf1

$\begin{array}{cc}\text { 흔 } & \text { Ncf2 } \\ \text { 른 } & \text { Nfkbib }\end{array}$

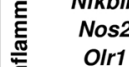

Olr1
Pecam1

Pla2g7

Ptafr

Ptgs1

Ptgs2

$5100 a 8$

Saa3

Spp1

Tnfrsf1a

\begin{tabular}{|c|c|}
\hline \multirow{11}{*}{ 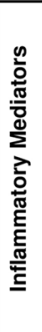 } & \\
\hline & Csf2 \\
\hline & Cxcl1 \\
\hline & Cxcl2 \\
\hline & Cxcl5 \\
\hline & IFNg \\
\hline & $1 / 10$ \\
\hline & $\begin{array}{l}171 a \\
\text { I/1b }\end{array}$ \\
\hline & 116 \\
\hline & Tgfb1 \\
\hline & Tnf \\
\hline \multirow{5}{*}{ 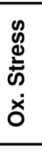 } & Gclc \\
\hline & Gsta1 \\
\hline & Hmox1 \\
\hline & Hsp70a1b \\
\hline & Sod3 \\
\hline
\end{tabular}
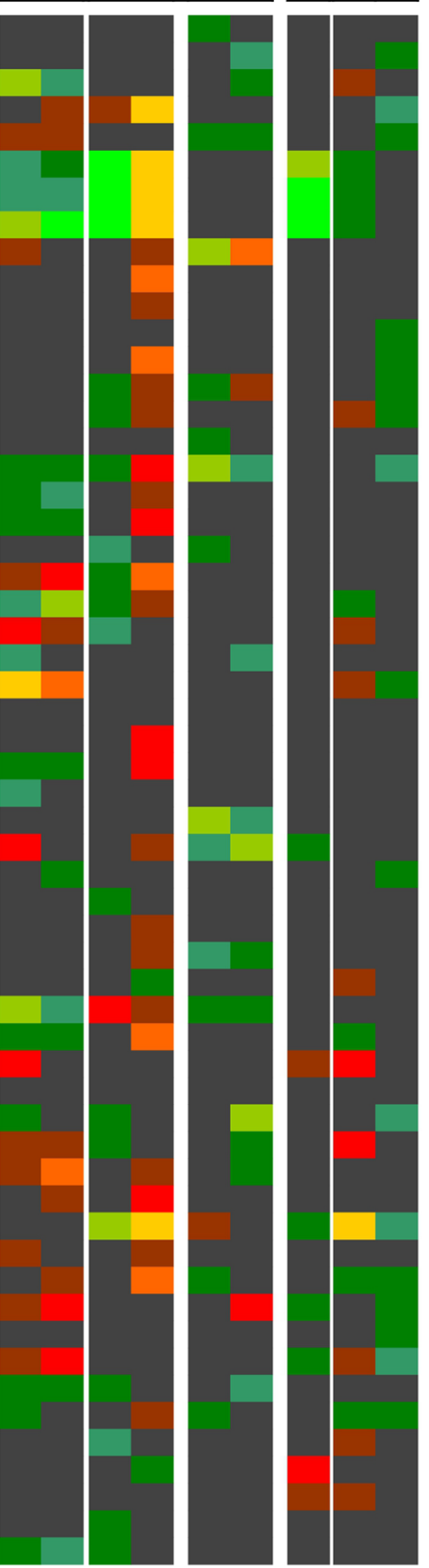

b

\begin{tabular}{|c|c|}
\hline 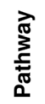 & $\begin{array}{l}\text { 동 } \\
\overleftarrow{2} \\
\text { के }\end{array}$ \\
\hline
\end{tabular}

高 $\overline{\text { T. }}$ ICAM-1

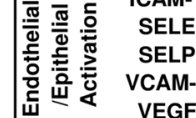

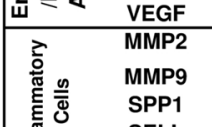

惡

TNF-R1

ADIPOQ

CCL2

CCL3

CCL4

CRP

CXCL1

CXCL2

는 $\quad$ GXCL12

IFN-g

$\sum$ IL-1b

$\underset{\frac{\pi}{0}}{\mathbb{2}}$ IL-1a

IL-6

IL-12(p40)

IL-13

IL-10

IL-1Ra

PDGF-BB

RETN

TGF-b1

\begin{tabular}{|c|c|c|c|}
\hline \multicolumn{2}{|c|}{ Inhalation } & \multicolumn{2}{|c|}{ Infusion } \\
\hline $\begin{array}{l}\frac{5}{\mathbb{N}} \\
\text { Ф્ }\end{array}$ & 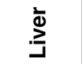 & $\begin{array}{l}\frac{t}{\mathbb{J}} \\
\text { I্ }\end{array}$ & 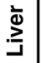 \\
\hline f $\frac{f}{\text { ज }}$ & f $\frac{f}{\text { ป }}$ & f & 与 \\
\hline
\end{tabular}
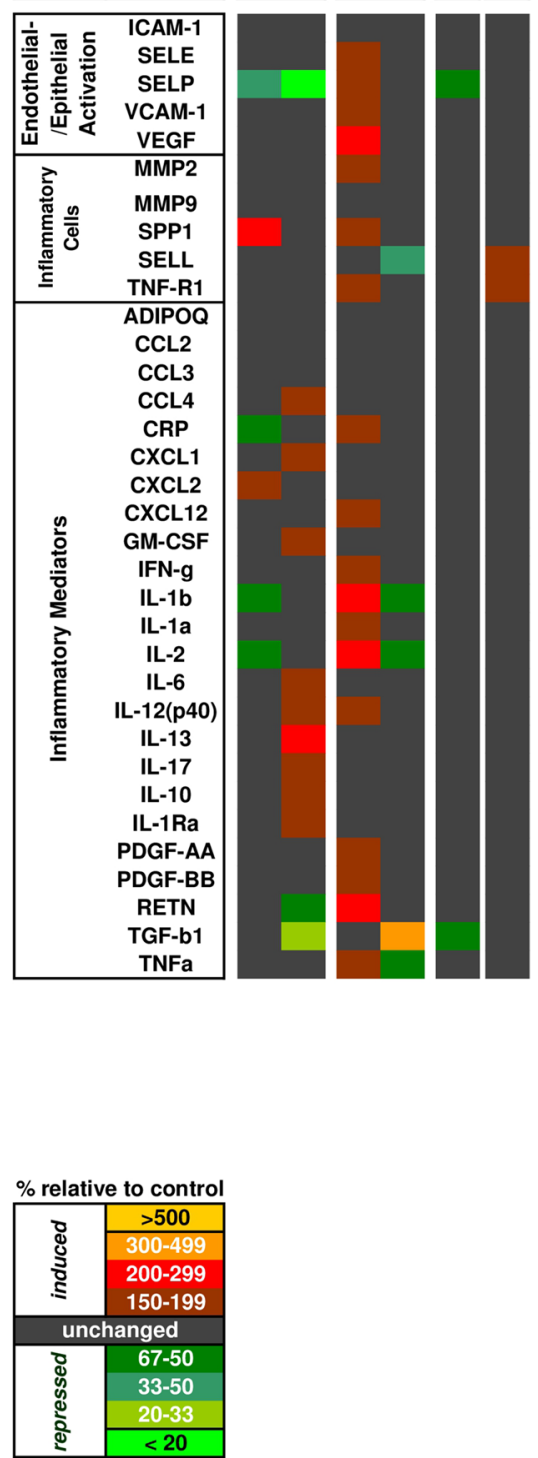

Fig. 6 Heatmap representation of the transcript (59 genes) and protein (34 analytes) panel profiling from heart, aorta and liver following carbon nanoparticle (CNP) inhalation ( $4 \mathrm{~h}$ and $24 \mathrm{~h}$ ) and intra-arterial infusion $(4 \mathrm{~h})$ comparing exposed versus control mice. a. Transcript expression levels of 59 genes representing epithelial/endothelial activation, inflammatory cell markers, inflammation mediators and oxidative stress of heart, aorta and liver are shown. b. Protein expression levels of 34 markers representing epithelial/endothelial activation, inflammatory cell markers, inflammation mediators of heart and liver are shown. Samples were pooled from 4 animals/experimental group for transcript and protein analysis. Expression values are provided as percentage relative to time matched control. Fold changes below 1.5 were considered insignificant and are indicated in black color. Ox. stress: Oxidative Stress 
numbers as well as a decline in circulating activated leucocytes. In spite of the fact that the observed pattern in this study matches well with the previously described platelet accumulation and fibrinogen deposition in the extrapulmonary microvasculature after CNP inhalation [35], these findings are at this point only indicative of atherosclerotic susceptibility and warrant detailed mechanistic investigations to substantiate a link to disease onset or progression. Recently, Miller and colleagues [56] demonstrated the accumulation of inhaled gold nanoparticles $(<10 \mathrm{~nm})$ at the sites of vascular inflammation following translocation in a size dependent manner. This finding provides new evidence of a plausible contribution of translocated nanoparticles in the pathogenesis of atherosclerosis and cardiovascular diseases. In our IAI study however, where an inflammatory response in the lungs was bypassed and the retention of activated blood leukocytes was absent, much less thrombocytosis was observed, and the extra pulmonary organs of investigation failed to show a pro-inflammatory signature. To match that to the accumulation data from Miller and colleagues [56], it might be considered that we used young and healthy mice, with now vascular lesions, and that particles, smaller than $10 \mathrm{~nm}$ may have more profound effects on extra-pulmonary organs. Nevertheless our study indicates the aortic tissue to be a susceptible organ for extra-pulmonary particle effects.

Taken together, our data shows that CNP inhalation induced a very mild inflammatory response in the lung but provoked clear hematological alterations (increased numbers of circulating neutrophils and platelets, concomitant with a decline in circulating activated leucocytes) and clearly demarcating transcript expression changes in aorta pointing to an inflammatory systemic irritation after $24 \mathrm{~h}$ inhalation. In comparison, although many endpoints were addressed, intra-arterial infusion of CNP induced only a very modest systemic response. Thus, we conclude that indirect (local particle-cell interactions in the lung) rather than direct effects due to translocated CNP are mainly governing the observed systemic effects. Taking into account the results from our previous study on platelet accumulation in the hepatic microvasculature [36] using identical inhalation exposure settings $\left(440 \mu \mathrm{g} / \mathrm{m}^{3}\right.$, mass median diameter $72 \mathrm{~nm}$ ), we suggest that the extrapulmonary pro-thrombogenic effects represent the most sensitive response to CNP inhalation. These prothrombogenic effects may occur even in absence of any detectable pulmonary or systemic inflammation as previously reported [31, 35]. The lack of any signs for extrapulmonary inflammation reported by the Khandoga et al., [35] study might be related to the use of C57BL/6 mice, which are less prone to inflammatory reactions than the $\mathrm{BALB} / \mathrm{c}$ mice used here.

\section{Limitations of the study}

For technical reasons two different types of CNP had to be used for inhalation (spark-discharge lab-generated CNP) and IAI (Printex90) exposure. While this may be considered as a weakness of the current study, there is compelling evidence that both CNP types are very similar in terms of organic carbon content, oxidative potency measured as ascorbic acid consumption (cell free) and induction of lipoperoxidation in macrophages, when expressed on a surface area basis [45]. Moreover, using BET surface area is used as dose metric both CNP types have been shown to display virtually identical proinflammatory potencies (summarized in Additional file 1: Table S8) suggesting similar underlying pathways of toxicity [28]. Intratracheal delivery of both CNPs types into mice, equally affected peripheral blood cell numbers and similarly as shown in Fig. 3. This compliant pattern for spark-discharge and Printex 90 material, further supports the comparability of the two CNPs. Nevertheless, the extra pulmonary effects of inhaled Printex 90 or intra-arterially infused Palas particles remain hidden, and the use of different CNP materials remains a weak spot of the study which cannot be overlooked. To consider the resulting uncertainties we have aimed for a conservative dose adjustment and applied a maximal reasonable translocated fraction of inhaled CNP by IAI, so as not to underestimate the potential direct effects. Therefore, we argue that adjusting the IAI-delivered systemic CNP surface area dose to the upper limit of systemically available (translocated) CNPs after inhalation $\left(30 \mathrm{~mm}^{2}\right)$ allows a comparison of direct and indirect CNP effects at equivalent doses $[41,57]$. Considering that on the one hand IAI-induced effects are smaller than those induced by inhaled CNPs, while on the other hand the CNP dose delivered via IAI is larger for a given period of time than the systemically available CNP dose after inhalation, we argue that the lack of response after IAI application cannot be seen as a result of low IAI dosing. Instead, we consider the lack of response after IAI suggests that particle-cell interactions in the lung (indirect effect), to represent the key event of the observed extra-pulmonary pro-thrombogenic effects following CNP inhalation. Another limiting factor could be that interactions of the Krebs-Henseleit buffer (IAI vehicle) with the suspended Printex90 particles may have altered the surface properties of the IAI delivered CNPs as compared to the inhaled-translocated CNPs. In $2 \%$ serum dispersed Printex90 CNPs, however can even enhance acute pulmonary inflammation upon instillation in comparison to pure water dispersions (unpublished observation). Nevertheless, the very same IAI application of these Printex CNPs was able to cause systemic effects in the hepatic microvasculature [34], arguing against persistent passivation of Printex90 particle by incubation in KrebsHenseleit buffer. It is also possible that the higher stability 
of Printex90 in aqueous media to be due to hydrophilic surface properties (e,g, high abundance of oxygenated functionalities) which could likely be absent in the spark discharge generated CNPs that appear to be more hydrophobic. Moreover, a purity of $95-98 \%$ may correspond to significant differences of $2-5 \%$ impurity, is located particularly on the surface of particles. These differences in particle characteristics between Printex 90 and spark discharge generated may be considered as possible confounding factors.

Another potential drawback of the present study may be the influence of the surgical procedure required for IAI of CNPs which may have potential influence on the expression of protein markers and transcripts. Also, we focused the IAI- induced analysis on the $4 \mathrm{~h}$ time window because our previous studies indicated a $2 \mathrm{~h}$ interval to be sufficient for platelet accumulation in the hepatic microvasculature [34]. Pooling of samples for transcript and protein analysis may also induce false positives and negatives due to high inter sample variation in one group, such as extreme high or low values in one or two samples. To further reduce the impact of individual variations, we focused our analysis on changes observed for marker patterns, in order to achieve a more integral view. Additionally, though our present findings following $4 \mathrm{~h}$ IAI exhibited no substantial response, and also previous IAI results [34] do not demand for investigations at later time points, yet we consider that using additional animals to obtain IAI data at $24 \mathrm{~h}$ might have been ideal to exclude that later response have not been overlooked.

In spite of the limitations listed above, we are not aware of any other study that allows for similar types of conclusions and a direct comparison of dose-equivalent systemic effects after inhalation-translocation and IAI of CNPs. The methodological strength of the present study is that the intra-arterially infused CNP dose was chosen to match the estimated dose translocated from the lung epithelium into the circulation after inhalation, so that in the former case the particles circumvent pulmonary accumulation and possible release of inflammatory mediators from the parenchyma of the lung. Finally, it is noteworthy that our results are consistent with the human inhalation exposure study using identical sparkdischarge generated CNP, which reported alterations of peripheral blood leukocyte distribution and expression of adhesion molecules consistent with increased leukocyte retention in the vascular bed [36]. However, in a real-life exposure scenario, ambient particulate matter will represent exposure a mixture of particles, gases, volatile organic compounds etc. This can only be mimicked by using collected ambient dust. Thus, the exposure scenario used in the current experimental set up is restricted to the toxicology of insoluble CNPs.

\section{Conclusion}

This study shows that intra-arterial infusion of CNPs induced only mild early effects in secondary (non-pulmonary) target organs whereas inhalation of CNPs resulted in both pulmonary and extra-pulmonary (particularly in the aorta) responses. This indicates that the extrapulmonary effects after CNP inhalation require local, pulmonary particle-cell interactions (indirect effect) and that the translocated CNPs (direct effect) appear to be of minor importance for the effects detected in extrapulmonary targets. Interestingly, the molecular signature of the aorta proved to be most affected among the investigated extra-pulmonary tissues, displaying strong proinflammatory reactions coupled with increased levels of markers of atherosclerosis and endothelial dysfunction. However, these findings are only indicative of potential susceptibility that warrants detailed pathomechanistic investigations as vascular dysfunction has not been investigated here. Our data demonstrates that inhalationmediated specific particle-lung cell interactions following CNP exposure might alter the systemic homeostasis leading to the retention of activated blood leucocytes in the pulmonary vascular bed and might induce a set of extra-pulmonary molecular reactions. Finally, the significant effect observed in the aortic tissue suggests the aorta to be an important extra-pulmonary target of CNP-mediated effects following the pulmonary response to inhaled CNPs that warrants more detailed investigations in future studies.

\section{Methods \\ Animals}

Female BALB/cJ mice (10-12 weeks) housed under specific pathogen free conditions at the animal facility of the Helmholtz Zentrum München were used for the experiments. The inhalation and IAI groups consisted of $n=16$ and $n=6$ animals, respectively, for each of the experimental groups per time point. All experimental procedures were approved by the Bavarian Animal Research Authority (Approval no: 55.2-1-54-2531-115-05) in accordance with German law of animal protection. Animal numbers, experimental groups and overall experimental design are described in Additional file 1: Table S8 and Fig. 7.

\section{Particle types used for inhalation and intra-arterial infusion (IAI)}

Ideally, identical CNPs should be used for inhalation and IAI exposure. For delivery of the highest possible lungdeposited CNP (surface area) dose rate in the ultrafine size range $(<100 \mathrm{~nm})$ via inhalation laboratory-generated spark-discharge CNP aerosol is the most suitable particle type [58]. Unfortunately, this particle type revealed to be not sufficiently stable in the Krebs-Henseleit buffer, the 


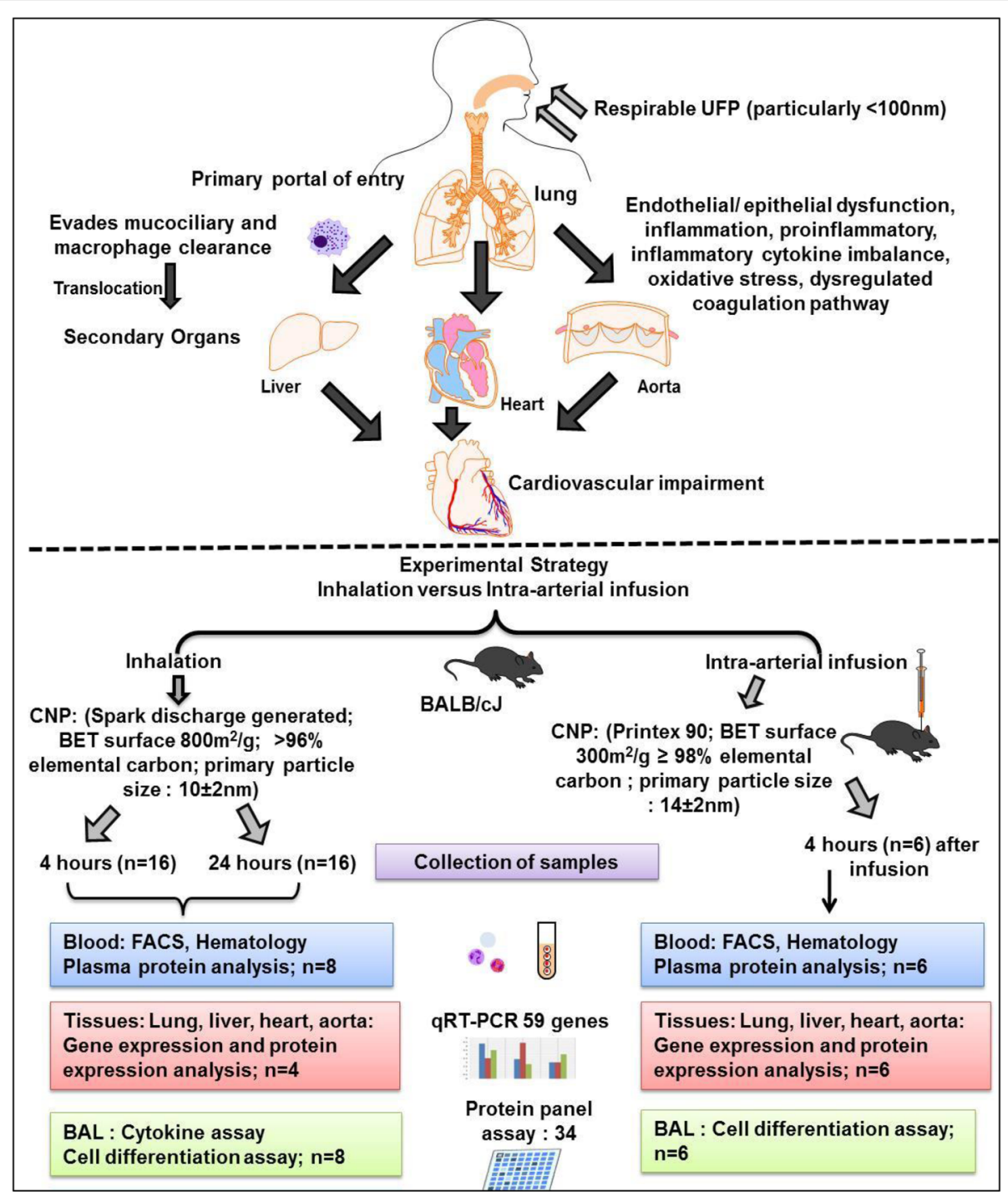

Fig. 7 Schematic representation of the experimental strategy. The figure outlines the rationale and corresponding experimental strategy to compare and contrast the pulmonary and extra-pulmonary effects of carbon nanoparticle (CNP) exposure following inhalation and intraarterial infusion in BALB/CJ mice. BAL: bronchoalveolar lavage; BET: Brunauer-Emmett-Teller; CNP: carbon nanoparticle; FACS: fluorescence automated cell sorting

vehicle used for IAI application, and thus the previously used [34] commercially available carbon nanoparticles (Printex 90, Degussa, Frankfurt, Germany) were used for IAI exposure. These two types of particles have very similar physicochemical properties (spark discharge/Printex $90 \mathrm{CNPs}$ ), namely chemical composition $(\geq 98 \% / \geq 95 \%$ elemental carbon, no bioavailable organic compounds), agglomerated spherical primary carbon particles with primary particle diameter of $10 \pm 2 \mathrm{~nm} / 14 \pm 2 \mathrm{~nm}$; Brunauer-Emmett-Teller (BET) surface area of $800 \mathrm{~m}^{2} / \mathrm{g} / 300 \mathrm{~m}^{2} / \mathrm{g}$ [24, 44, 45 , 59]. Importantly, for both types of highly pure carbon particles the acute pulmonary toxicity in mice scales extremely well with BET surface area [44] and is directly related to the pro-oxidative surface activity, i.e., the surface specific toxicity is identical among the two types of CNPs [28]. These particle characteristics are summarized in the Additional file 1: Table S9. The preference of surface area as most predictive dose metric (rather than mass or number) for acute pulmonary effects, has not only been shown for a wide variety of carbonaceous but also for metal oxide and polymeric materials $[60,61]$. Thus, BET surface area was used as dose metric to determine an equivalent dose of infused CNPs (Printex 90; mass-specific BET surface area: $300 \mathrm{~m}^{2} / \mathrm{g}$ ) corresponding to the translocated dose of CNPs (spark discharge; $800 \mathrm{~m}^{2} / \mathrm{g}$ ) after inhalation exposure $[28,44]$. 
Inhalation of CNPs: The set-up of the whole-body exposure system for rodents used in this study has been previously described [30, 62]. Mice $(n=16)$ were simultaneously exposed for 4 or $24 \mathrm{~h}$ to either filtered air or spark discharge generated CNPs at a mass concentration of $440 \mu \mathrm{g} / \mathrm{m}^{3}$ corresponding to a BET surface area concentration of $3.5 \times 10^{5} \mathrm{~mm}^{2} / \mathrm{m}^{3}$ with a number- and mass-based median diameter of 48 and $72 \mathrm{~nm}$, respectively, and a geometric standard deviation (width) of the size distribution of 1.55. For these conditions, more than $80 \%$ of the CNP mass is in the ultrafine size range (below $100 \mathrm{~nm}$ ). Please refer to Additional file 1 for more details.

\section{Translocated surface area dose after CNP inhalation}

For assessment of the role of direct systemic particle effects after inhalation exposure, CNPs were intraarterially infused (IAI) directly into the blood stream. The infused CNP surface area dose was chosen to match the CNP dose likely to be translocated from the lung to the blood stream during a $24 \mathrm{~h}$ inhalation exposure. As a worst case scenario the maximal translocated particle dose was estimated from the inhaled CNP surface area concentration $\left(3.5 \times 10^{5} \mathrm{~mm}^{2} / \mathrm{m}^{3}\right)$ and literature values for the inhaled air volume during 24 inhalation $(66 \mathrm{ml} /$ $\min \times 24 \mathrm{~h}=0.095 \mathrm{~m}^{3}$ ) [63]; the lung deposited aerosol fraction of $34 \%$ for nanoparticles with a similar size distribution as used here [64] and the translocated fraction of the lung deposited dose of $0.3 \%$, which implies that the lung deposited surface area dose is 330-fold higher $\left(10,000 \mathrm{~mm}^{2}\right)$ than the translocated dose. This number is derived from $0.1 \%$ translocation according to Kreyling et al., [23] and a safety factor of 3 accounting for uncertainties due to differences in particle type and animal model). As all of the relevant parameters were estimated conservatively (towards the highest possible dose, the resulting translocated dose of $30 \mathrm{~mm}^{2}$ for $24 \mathrm{~h} \mathrm{CNP}$ inhalation can be considered an upper limit of the translocated CNP dose [Additional file 1, extended materials and methods].

\section{IAI of CNP}

For IAI, commercially available CNPs (Printex 90, Degussa, Frankfurt, Germany), suspended in $200 \mu \mathrm{l}$ Krebs-Henseleit buffer, were infused in mice $(n=6)$ through a catheter introduced into the aortic arch via the carotid artery and analyzed after $4 \mathrm{~h}$. Mice intraarterially infused with only Krebs-Henseleit buffer (i.e., vehicle) served as the corresponding control [34], [Additional file 1, extended materials and methods].

Similar to the inhalation route, more than $50 \%$ of the applied (agglomerated) CNPs mass was in the ultrafine size range (UfCP, mass-weighted (mobility) diameter below $100 \mathrm{~nm}$ ). This was accomplished by carefully processing the initial CNPs suspension according to a sequence of filtration and vortexing steps [65]. For comparison of the biological response of inhaledtranslocated and intra-arterially infused CNPs both doses were matched. Using the dosimetry method for CNPs described by Stampfl et al. [65] $30 \mathrm{~mm}^{2}$ of CNPs, which corresponds to $110 \mathrm{ng}$ of CNPs (300 $\mathrm{m}^{2} / \mathrm{g}$ for Printex 90), were infused representing the maximum dose of inhaled-translocated CNPs as described above. Thus, the observed biological effects after intra-arterial infusion represents an upper limit of the expected direct effect of particle translocation from the lung to the blood stream after $24 \mathrm{~h}$ CNP inhalation (and even more so after $4 \mathrm{~h}$ inhalation).

\section{Animal procedures and molecular analysis}

Mice were anesthetized by intraperitoneal injection of xylazine $(4.1 \mu \mathrm{g} / \mathrm{g})$ and ketamine $(188.3 \mu \mathrm{g} / \mathrm{g})$, blood was withdrawn from the retro-orbital plexus and collected in EDTA tubes (Sarstedt, Hannover, Germany) followed by exsanguination and bronchoalveolar lavage (BAL) as previously described [44]. Analysis of BAL cell differentials, BAL total protein content, hematology, and lung histology was performed. To abide by the " $3 R$ " (replace, reduce and refine) principles of animal protection, inflammatory response in the lungs of IAI exposed mice was assessed based on the most sensitive method in a minimal number of mice, namely expression analysis only (no BAL analysis), since only very low pulmonary effects were expected. Transcript and/or protein expression analysis for both control and experimental groups ( $4 \mathrm{~h}$ and $24 \mathrm{~h}$ inhalation, $4 \mathrm{~h}$ intra-arterial infusion) were performed using BAL fluid, plasma, lung, heart, liver, and aorta using panel assays as described in the supplementary section. Blood samples were also analyzed for monocyte and granulocyte activation using flow cytometry (LSR II, Becton Dickinson) and FlowJo Software (Version:7.2.2, Tree Star, Oregon). Granulocytes were defined as $\left[\mathrm{GR} 1^{+} \mathrm{Ly}_{6 \mathrm{G}}{ }^{+}\right]$and monocytes as $\left[\mathrm{GR} 1^{+} \mathrm{Ly}_{6 \mathrm{G}}{ }^{-}\right]$ cells. Additionally, we also investigated three integrin cell surface markers, namely integrin alpha $M(C D 11 b)$, alpha-4 integrin (CD49d) and beta-2 integrin (CD18) due to their established role in leukocyte-endothelial interaction and their association with human particle inhalation [36]. For transcript and protein expression analysis, samples were pooled from 4-6 animals for each experimental group.

\section{Statistical analysis}

Statistical analysis was performed by student's t-test comparing time-matched control and CNP exposed groups. Statistical significance was set at $p<0.05$. Values are given as mean \pm standard error of the mean (SEM). CNP exposure-related effects are typically expressed as changes relative to the time matched control. 


\section{Additional file}

Additional file 1: Table S1. Summary of the main findings following carbon nanoparticle (CNP) inhalation and intra-arterial infusion in BALB/CJ mice. $\uparrow$ : Increased $\downarrow$ : Decreased. Table S2: BAL cell differentials are shown in counts 4 and $24 \mathrm{~h}$ after clean air (Contol) or carbon nanoparticle (CNP) inhalation. Values measured out of range were defined as: <OOR. Macro: macrophages, Lympho: Iymphocytes, Neutro: neutrophil granulocyte, EOS: eosinophil. Means \pm SEM, Inhalation: $n=8$; infusion: $n=6$; * $p \leq 0.05$. Table S3: BAL cytokine concentrations: Protein markers in BAL samples of mice $4 \mathrm{~h}$ and $24 \mathrm{~h}$ after clean air (Control) or carbon nanoparticle (CNP) inhalation. Values measured out of range were defined as: $<O O R$. CCL2: Monocyte chemoattractant protein-1 (MCP-1), CXCL1: Growthregulated alpha protein (KC), G-CSF: Granulocyte colony stimulating factor, GM-CSF: Granulocyte-macrophage colony stimulating factor 2, IFN-gamma: Interferon gamma, IL: Interleukin, TNF-alpha: Tumor necrosis factor alpha. Mean \pm SEM, ${ }^{*} p \leq 0.05 . n=8$. Table S4: Gene annotation and primer sequences of the transcripts analyzed: List of the 59 transcripts analyzed by quantitative RT-PCR with respective primer pairs. Expression of Hprt1 expression served as control. Table S5: Haematological analysis Haematological analysis of blood samples 4 and $24 \mathrm{~h}$ after clean air (Control) or carbon nanoparticle (CNP) inhalation and $4 \mathrm{~h}$ after sham (Control) or CNP infusion. RBC: red blood cells, WBC: white blood cells, Lympho: lymphocytes, Neutro: neutrophil granulocyte, EOS: eosinophil granulocyte, Baso: basophil granulocyte, Mono: monocytes, PLT: platelets, Large PLT: large platelets. Means \pm SEM, * $p<0.05$. Inhalation: $n=8 /$ group; Infusion: $n=6 /$ group. Table S6: Multiplex protein suspension array Protein markers in plasma samples of mice 4 and $24 \mathrm{~h}$ after clean air (Control) or carbon nanoparticle (CNP) inhalation and $4 \mathrm{~h}$ after sham (Control) or CNP infusion. Values measured out of range were defined as: <OOR. CCL2: Monocyte chemoattractant protein-1 (MCP-1), CCL5: RANTES, CXCL1: Growth-regulated alpha protein (KC), E-selectin: Endothelial leukocyte adhesion molecule 1, G-CSF: Granulocyte colony stimulating factor, GM-CSF: Granulocyte-macrophage colony stimulating factor 2, IFN-gamma: Interferon gamma, IL: Interleukin, MMP9: Matrix metalloproteinase-9, sICAM-1: soluble Intercellular adhesion molecule 1, sVCAM-1: soluble Vascular adhesion molecule 1, TNF-alpha: Tumor necrosis factor alpha, total PAI-1: total Plasminogen activator inhibitor 1. Inhalation: $n=8$; infusion: $n=6$; Mean \pm SEM, ${ }^{*} p<0,05$. Table S7: Multiplex protein expression Protein expression analysis (pg/ml) of lung, heart and liver tissue 4 and $24 \mathrm{~h}$ after clean air (Control) or carbon nanoparticle (CNP) inhalation and $4 \mathrm{~h}$ after sham (Control) or CNP infusion. CCL2: Monocyte chemoattractant protein-1 (MCP-1), CCL3: MIP-1-alpha, CCL4: MIP-1-beta, CRP: C-reactive protein. CXCL1: Growth-regulated alpha protein (KC), CXCL2: Macrophage inflammatory protein 2 (MIP2), CXCL12: Stromal cell-derived factor 1 (SDF-1), E-selectin: Endothelial leukocyte adhesion molecule 1, GM-CSF: Granulocytemacrophage colony stimulating factor 2, ICAM-1: Intercellular adhesion molecule 1, IFN-gamma: Interferon gamma, IL: Interleukin, L-selectin: Leukocyte adhesion molecule 1 (CD62 L antigen), MMP2: Matrix metalloproteinase-2, MMP9: Matrix metalloproteinase-9, PDGF-AA: Platelet-derived growth factor A chain (dimer), PDGF-BB: Platelet-derived growth factor B chains (dimer), Pselectin: Leukocyte-endothelial cell adhesion molecule 3 (CD62P antigen), TGFbeta-1: Transforming growth factor beta-1, TNF-alpha: Tumor necrosis factor alpha, TNF-RI: Tumor necrosis factor receptor superfamily member 1A, VCAM1: Vascular adhesion molecule 1, VEGF: Vascular endothelial growth factor. Samples were pooled from 4 animals/experimental group for gene and protein analysis. Table S8: Animal distribution for each experiment. CNP: Carbon nanoparticle; FACS: Fluorescence automated cell sorter. Table S9: Comparison of the properties form Printex $90(\mathrm{IAI})$ and Palas spark-discharge (Inhalation) carbon nanoparticles (CNP). (DOCX 106 kb)

\section{Abbreviations}

Alox5: Arachidonate 5-lipoxygenase; BAL: Bronchoalveolar lavage; BET: Method by Brunauer-Emmett-Teller for determining particle surface area by physical adsorption of gas molecules on a solid surface; CCL: CCchemokine ligand; CD11b: Integrin alpha M; CD18: beta-2 integrin; CD49d: alpha-4 integrin; CNP: Carbon nanoparticles; CXCL: Chemokine (C-X-C motif) ligand; Emr1: Adhesion G protein-coupled receptor E1 (Adgre1: F4/80); GM-CSF: Granulocyte-macrophage colony-stimulating factor; IAl: Intra-arterial infusion; IL: Interleukin; Lcn2: Lipocalin 2; Lgals3: Galectin 3;
Ly6g: Lymphocyte antigen 6 complex: locus G; MPC: Mean platelet component; MPM: Mean platelet mas; MPV: Mean platelet volume; Ncf1, -2: Neutrophil cytosolic factor 1, -2; NP: Nanoparticles; Olr1: Oxidized low density lipoprotein; PAI-1: Plasminogen activator inhibitor-1; PCDW: Platelet component distribution width; PM: Particulate matter; PTC: Plateletcrit; Saa3: Serum amyloid A 3; SEM: Standard error of the mean;

SHRs: Spontaneously hypertensive rats; Spp1: Secreted phosphoprotein 1

(Osteopontin); UfCPs: Ultrafine carbon particles

\section{Acknowledgements}

We are grateful to all members of our animal facility and the research associates Birgit Frankenberger and David Kutschke for their expert technical assistance. We also thank the members of our institutes for helpful discussions.

\section{Funding}

VINNOVA (2016-01951) (K.G.).

\section{Availability of data and materials}

Additional supporting data are shared as supplementary material: Additional file 1 (pdf).

\section{Authors' contributions}

TS, HS, OS, WKG and FK conceived and designed the project; DE, ST, TA, EK performed the experiments; KG, SU, HS, OS and TS analyzed the data; KG, SU, $\mathrm{HS}$, OS,TS wrote the manuscript. All authors read and approved the final manuscript.

\section{Competing interests}

The authors declare no competing financial interest.

\section{Consent for publication}

Not applicable.

\section{Ethics approval and consent to participate}

All animal experiments were in compliance with protocols approved by the local Animal Care and Use Committee (District Government of Upper Bavaria; permit number 55 2-1-54-2531-115-05).

\section{Author details}

${ }^{1}$ Unit of Lung and Airway Research, Institute of Environmental Medicine (IMM), Karolinska Institutet, SE-171 77 Stockholm, Sweden. ${ }^{2}$ Unit of Work Environment Toxicology, Institute of Environmental Medicine (IMM), Karolinska Institutet, SE-171 77 Stockholm, Sweden. ${ }^{3}$ Institute of Lung Biology and Disease, Comprehensive Pneumology Center, Helmholtz Zentrum München, German Research Center for Environmental Health, D85764 Neuherberg, Germany. ${ }^{4}$ German Mouse Clinic, Institute of Experimental Genetics, Helmholtz Zentrum München, German Research Center for Environmental Health, D85764 Neuherberg, Germany. ${ }^{5}$ Cooperationgroup Comprehensive Molecular Analytics (CMA), Joint Mass Spectrometry Centre (JMSC), Helmholtz Zentrum München, German Research Center for Environmental Health, D85764 Neuherberg, Germany. ${ }^{6}$ Walter Brendel Centre of Experimental Medicine, Ludwig-Maximilians-Universität, D81377 Munich, Germany. ${ }^{7}$ Institute of Epidemiology I, Helmholtz Zentrum München, German Research Center for Environmental Health, D85764 Neuherberg, Germany. ${ }^{8}$ Comprehensive Pneumology Center Munich (CPC-M), Member of the German Center for Lung Research, D85764 Munich, Germany.

Received: 20 December 2016 Accepted: 8 June 2017 Published online: 20 June 2017

\section{References}

1. Dockery DW, Pope CA III, Xu X, Spengler JD, Ware JH, Fay ME, et al. An association between air pollution and mortality in six US cities. N Engl J Med. 1993;329:1753-9.

2. Samet JM, Dominici F, Curriero FC, Coursac I, Zeger SL. Fine particulate air pollution and mortality in 20 US cities1987-1994. N Engl J Med. 2000;343:1742-9.

3. Pope CA 3rd. Epidemiology of fine particulate air pollution and human health: biologic mechanisms and who's at risk? Environ Health Perspect. 2000;108(Suppl 4):713-23. 
4. Peters A, von Klot S, Heier M, Trentinaglia I, Cyrys J, Hörmann A, et al. Particulate air pollution and nonfatal cardiac events. Part I. Air pollution, personal activities, and onset of myocardial infarction in a case-crossover study. Res Rep Health Eff Inst. 2005;124:1-66. discussion 67-82, 141-148

5. WHO: The World Health Report. Reducing Risks, Promoting Healthy Life. Geneva, Switzerland: World Health Organisation 2002.

6. Peters A, Verrier RL, Schwartz J, Gold DR, Mittleman M, Baliff J, et al. Air Pollution and Incidence of Cardiac Arrythmia. Epidemiology. 2000;11:11-7.

7. Peters A, Dockery DW, Muller JE, Mittleman MA. Increased particulate air pollution and the triggering of myocardial infarction. Circulation. 2001;103:2810-5.

8. Pope CA 3rd, Burnett RT, Thurston GD, Thun MJ, Calle EE, Krewski D, et al. Cardiovascular mortality and long-term exposure to particulate air pollution: epidemiological evidence of general pathophysiological pathways of disease. Circulation. 2004;109:71-7.

9. Hoek G, Krishnan RM, Beelen R, Peters A, Ostro B, Brunekreef B, et al. Longterm air pollution exposure and cardio-respiratory mortality: a review. Environ Health. 2013;12:43. doi:10.1186/1476-069X-12-43.

10. Prüss-Üstün Annette, Wolf J, Corvalán Carlos F, Bos R, Neira, Maria Purificación; Preventing disease through healthy environments: a global assessment of the burden of disease from environmental risks, World Health Organization. ISBN 978924156519 6; 2016.

11. Seaton A, MacNee W, Donaldson K, Godden D. Particulate air pollution and acute health effects. Lancet. 1995;345:176-8.

12. Chalupa DC, Morrow PE, Oberdörster G, Utell MJ, Frampton MW. Ultrafine particle deposition in sub- jects with asthma. Environ Health Perspect. 2004;112:879-82.

13. Daigle CC, Chalupa DC, Gibb FR, Morrow PE, Oberdörster G, Utell MJ, et al. Ultrafine particle deposition in humans during rest and exercise. Inhal Toxicol. 2003;15(6):539-52.

14. Brown DM, Wilson MR, MacNee W, Stone V, Donaldson K. Size-dependent pro-inflammatory effects of ultrafine polystyrene particles: a role for surface area and oxidative stress in the enhanced activity of ultrafines. Toxicol Appl Pharmacol. 2001;175:191-9.

15. Li N, Sioutas C, Cho A, Schmitz D, Misra C, Sempf J, et al. Ultrafine particulate pollutants induce oxidative stress and mitochondrial damage. Environ Health Perspect. 2003;111:455-60.

16. Li XY, Brown D, Smith S, Macnee W, Donaldson K. Short-term inflammatory responses following intratracheal instillation of fine and ultrafine carbon black in rats. Inhal Toxicol. 1999;11:709-31.

17. Oberdorster G, Oberdorster E, Oberdorster J. Nanotoxicology: an emerging discipline evolving from studies of ultrafine particles. Environ Health Perspect. 2005;113:823-39.

18. Stearns RC, Murthy GGK, Skornik W, Hatch V, Katler M, Godleski JJ. 1994. Detection of ultrafine copper oxide particles in the lungs of hamsters by electron spectroscopic imaging. In: Proceedings of ICEM 13-PARIS, 1994 (Jouffrey B, Colliex C, eds). Paris: Les Editions de Physique, 763-764.

19. Geiser M, Rothen-Rutishauser B, Kapp N, Schurch S, Kreyling W, Schulz H, et al. Ultrafine particles cross cellular membranes by nonphagocytic mechanisms in lungs and in cultured cells. Environ Health Perspect. 2005;113:1555-60.

20. Oberdörster G, Sharp Z, Attudorei V, Elder A, Gelein R, Lunts A, et al. Extrapulmonary translocation of ultrafine carbon particles following wholebody inhalation exposure of rats. J Toxicol Environ Health A. 2002;65:1531-43.

21. Mills NL, Amin N, Robinson SD, Anand A, Davies J, Patel D, et al. Newby DE; Do inhaled carbon nanoparticles translocate directly into the circulation in humans? Am J Respir Crit Care Med. 2006;173(4):426-31.

22. Takenaka S, Karg E, Roth C, Schulz H, Ziesenis A, Heinzmann U, et al Pulmonary and systemic distribution of inhaled ultrafine silver particles in rats. Environ Health Perspect. 2001;109:547-51.

23. Kreyling WG, Hirn S, Moller W, Schleh C, Wenk A, Celik G, et al. Air-blood barrier translocation of tracheally instilled gold nanoparticles inversely depends on particle size. ACS Nano. 2014;28:222-33.

24. Elder A, Gelein R, Silva V, Feikert T, Opanashuk L, Carter J, et al. Translocation of inhaled ultrafine manganese oxide particles to the central nervous system. Environ Health Perspect. 2006;114:1172-8.

25. Ning Z, Geller MD, Moore KF, Sheesley R, Schauer JJ, Sioutas C. Daily variation in chemical characteristics of urban ultrafine aerosols and inference of their sources. Environ Sci Technol. 2007:41(17):6000-6.

26. Müller JO, Su DS, Jentoft RE, Wild U, Schlögl R. Diesel engine exhaust emission: oxidative behavior and microstructure of black smoke soot particulate. Environ Sci Technol. 2006;40(4):1231-6.
27. BéruBé K, Balharry D, Sexton K, Koshy L, Jones T. Combustion- derived nanoparticles: mechanisms of pulmonary toxicity. ClinExpPharmacolPhysiol. 2007;34(10):1044-50.

28. Stoeger T, Takenaka S, Frankenberger B, Ritter B, Karg E, Maier K, et al. Deducing in vivo toxicity of combustion- derived nanoparticles from a cellfree oxidative potency assay and metabolic activation of organic compounds. Environ Health Perspect. 2009;117:54-60.

29. Su DS, Jentoft RE, Muller JO, Rothe D, Jacob E, Simpson CD, et al. Microstructure and oxidation behaviour of Euro IV diesel engine soot: a comparative study with synthetic model soot sub- stances. Catal Today. 2004;90(suppl 1):127-32.

30. Upadhyay S, Stoeger T, George L, Schladweiler MC, Kodavanti U, et al. Ultrafine carbon particle mediated cardiovascular impairment of aged spontaneously hypertensive rats. Part Fibre Toxicol. 2014;11:36.

31. Andre E, Stoeger T, Takenaka S, Bahnweg M, Ritter B, Karg E, et al. Inhalation of ultrafine carbon particles triggers biphasic pro-inflammatory response in the mouse lung. Eur Respir J. 2006:28:275-85.

32. Upadhyay S, Stoeger T, Harder V, Thomas RF, Schladweiler MC, SemmlerBehnke $M$, et al. Exposure to ultrafine carbon particles at levels below detectable pulmonary inflammation affects cardiovascular performance in spontaneously hypertensive rats. Part Fibre Toxicol. 2008:5:19.

33. Upadhyay S, Ganguly K, Stoeger T, Semmler-Bhenke M, Takenaka S, Kreyling WG, et al. Cardiovascular and inflammatory effects of intratracheally instilled ambient dust from Augsburg, Germany, in spontaneously hypertensive rats (SHRs). Part Fibre Toxicol. 2010;7:27

34. Khandoga A, Stampfl A, Takenaka S, Schulz H, Radykewicz R, Kreyling W, et al. Ultrafine particles exert prothrombotic but not inflammatory effects on the hepatic microcirculation in healthy mice in vivo. Circulation. 2004;109:1320-5.

35. Khandoga A, Stoeger T, Khandoga AG, Bihari P, Karg E, Ettehadieh D, et al. Platelet adhesion and fibrinogen deposition in murine microvessels upon inhalation of nanosized carbon particles. J Thromb Haemost. 2010;8(7):1632-40

36. Frampton MW, Stewart JC, Oberdörster G, Morrow PE, Chalupa D, Pietropaoli AP, et al. Inhalation of ultrafine particles alters blood leukocyte expression of adhesion molecules in humans. Environ Health Perspect. 2006;114:51-8.

37. Brook RD, Rajagopalan S, Pope CA 3rd, Brook JR, Bhatnagar A, Diez-Roux AV et al. Kaufman JD; Particulate matter air pollution and cardiovascular disease: An update to the scientific statement from the American Heart Association. Circulation. 2010;121(21):2331-7.

38. Ruckerl R, Ibald-Mulli A, Koenig W, Schneider A, Woelke G, Cyrys J, et al. Air pollution and markers of inflammation and coagulation in patients with coronary heart disease. Am J Respir Crit Care Med. 2006;173(4):432-41.

39. Brook RD, Franklin B, Cascio W, Hong YL, Howard G, Lipsett M, et al. Air pollution and cardiovascular disease - A statement for healthcare professionals from the expert panel on population and prevention science of the American Heart Association. Circulation. 2004;109:2655-71.

40. Kreyling WG, Semmler-Behnke M, Seitz J, Scymczak W, Wenk A, Mayer P, et al. Size dependence of the translocation of inhaled iridium and carbon nanoparticle aggregates from the lung of rats to the blood and secondary target organs. Inhal Toxicol. 2009;21:55-60.

41. Nemmar A, Vanbilloen $H$, Hoylaerts MF, Hoet PH, Verbruggen A, Nemery B. Passage of intratracheally instilled ultrafine particles from the lung into the systemic circulation in hamster. Am J Respir Crit Care Med. 2001;164(9):1665-8.

42. Radomski A, Jurasz P, Alonso-Escolano D, Drews M, Morandi M, Malinski T, et al. Nanoparticle-induced platelet aggregation and vascular thrombosis. $\mathrm{Br}$ J Pharmacol. 2005;146:882-93.

43. Nurkiewicz TR, Porter DW, Hubbs AF, Cumpston JL, Chen BT, Frazer DG, et al. Nanoparticle inhalation augments particle-dependent systemic microvascular dysfunction. Part Fibre Toxicol. 2008;5:1.

44. Stoeger T, Reinhard C, Takenaka S, Schroeppel A, Karg E, Ritter B, et al. Instillation of six different ultrafine carbon particles indicates a surface area threshold dose for acute lung inflammation in mice. Environ Health Perspect. 2006;114(3):328-33.

45. Matuschek G, Karg E, Schroppel A, Schulz H, Schmid O. Chemical investigation of eight different types of carbonaceous particles using thermos analytical techniques. Environ Sci Technol. 2007:41(24):8406-11.

46. Ganguly K, Upadhyay S, Irmler M, Takenaka S, Pukelsheim K, Beckers J, et al. Stoeger T; Pathway focused protein profiling indicates differential function 
for IL-1B, -18 and VEGF during initiation and resolution of lung inflammation evoked by carbon nanoparticle exposure in mice. Part Fibre Toxicol. 2009;6:3.

47. Ganguly K, Upadhyay S, Irmler M, Takenaka S, Pukelsheim K, Beckers J, et al. Schulz $\mathrm{H}$; Impaired resolution of inflammatory response in the lungs of JF1/ Msf mice following carbon nanoparticle instillation. Respir Res. 2011;12:94.

48. Chen S, Yin R, Mutze K, Yu Y, Takenaka S, Königshoff M. Stoeger T; No involvement of alveolar macrophages in the initiation of carbon nanoparticle induced acute lung inflammation in mice. Part FibreToxicol. 2016;13(1):33.

49. Kermanizadeh A, Balharry D, Wallin H, Loft S. Møller P; Nanomaterial translocation-the biokinetics, tissue accumulation, toxicity and fate of materials in secondary organs-a review. Crit Rev Toxicol. 2015;45(10):837-72.

50. Rabolli V, Badissi AA, Devosse R, Uwambayinema F, Yakoub Y, Palmai-Pallag $M$, et al. Huaux F; The alarmin IL-1a is a master cytokine in acute lung inflammation induced by silica micro- and nanoparticles. Part Fibre Toxicol. 2014;11:69.

51. Shapiro SD. Immunology: Mobilizing the army. Nature. 2003;421(6920):223-4.

52. Tabor CM, Shaw CA, Robertson S, Miller MR, Duffin R, Donaldson K, et al. Hadoke PW Platelet activation independent of pulmonary inflammation contributes to diesel exhaust particulate-induced promotion of arterial thrombosis. Part FibreToxicol. 2016;13:6.

53. Lefrançais E, Ortiz-Muñoz G, Caudrillier A, Mallavia B, Liu F, Sayah DM, et al. The lung is a site of platelet biogenesis and a reservoir for haematopoietic progenitors. Nature. 2017;544(7648):105-9.

54. Chen S, Su Y, Wang J. ROS-mediated platelet generation: a microenvironment-dependent manner for megakaryocyte proliferation, differentiation, and maturation. Cell Death Dis. 2013:4:e722.

55. Anderson GJ, Roswit WT, Holtzman MJ, Hogg JC, Van Eeden SF. Effect of mechanical deformation of neutrophils on their CD18/ICAM-1-dependent adhesion. J Appl Physiol. 2001;91:1084-90.

56. Miller MR, Raftis JB, Langrish JP, McLean SG, Samutrtai P, Connell SP, et al. Inhaled Nanoparticles Accumulate at Sites of Vascular Disease. ACS Nano. 2017;11(5):4542-52.

57. Schleh C, Holzwarth U, Hirn S, Wenk A, Simonelli F, Schäffler M, et al. Biodistribution of inhaled gold nanoparticles in mice and the influence of surfactant protein D. J Aerosol Med Pulm Drug Deliv. 2013;26(1):24-30.

58. Roth C, Ferron GA, Karg E, Lentner B, Schumann G, Takenaka S. Generation of Ultrafine Particles by Spark Discharging. Aerosol Sci Tech. 2004;38:228-35.

59. Frampton MW, Utell MJ, Zareba W, Oberdörster G, Cox C, Huang LS, et al. Effects of exposure to ultrafine carbon particles in healthy subjects and subjects with asthma. Res Rep Health Eff Inst. 2004;126:1-147.

60. Stoeger T, Schmid O, Takenaka S, Schulz H. Inflammatory response to TiO2 and Carbonaceous particles scales best with BET surface area. Environ Health Perspect. 2007;115(6):A290-1.

61. Schmid O, Stoeger T. Surface area is the biologically most effective dose metric for acute nanoparticle toxicity in the lung. J Aerosol Sci. 2016;99:133-43.

62. Karg E, Roth C, Heyder J. Do Inhaled Ultrafine Particles Cause Acute Health Effects in Rats? II: Exposure System. J Aerosol Sci. 1998;29:S315-6.

63. DeLorme MP. Moss OR; Pulmonary function assessment by whole-body plethysmography in restrained versus unrestrained mice. J Pharmacol Toxicol Methods. 2002:47(1):1-10.

64. Alessandrini F, Semmler-Behnke M, Jakob T, Schulz H, Behrendt H. Kreyling W; Total and regional deposition of ultrafine particles in a mouse model of allergic inflammation of the lung. InhalToxicol. 2008;20(6):585-93.

65. Stampfl A, Maier M, Radykewicz R, Reitmeir P, Göttlicher M. Niessner R.; Langendorff heart: a model system to study cardiovascular effects of engineered nanoparticles. ACS Nano. 2011;5(7):5345-53.

\section{Submit your next manuscript to BioMed Central and we will help you at every step:}

- We accept pre-submission inquiries

- Our selector tool helps you to find the most relevant journal

- We provide round the clock customer support

- Convenient online submission

- Thorough peer review

- Inclusion in PubMed and all major indexing services

- Maximum visibility for your research

Submit your manuscript at www.biomedcentral.com/submit

) Biomed Central 